\title{
Einleitung zum 14. Band
}

Der vorliegende Band umfaßt den Zeitraum November 1748 bis September 1749. In dessen Verlauf gab es zwei Ereignisse, die als Zäsuren in Gottscheds Leben betrachtet werden können. Am 30. Januar 1749 starb Ernst Christoph von Manteuffel. Als Gesprächspartner, Korrespondent, Nothelfer, Ermutiger und Mäzen war der bis zuletzt mit einflußreichen Politikern und respektablen Standesgenossen gut vernetzte Reichsgraf für Gottsched und ebenso für seine Frau über ein Jahrzehnt lang eine jederzeit erreichbare Größe, die in schwierigen Situationen Rückhalt und Anerkennung verschaffen konnte. Anerkennung und Respekt erfuhr das Ehepaar Gottsched im September des Jahres 1749 in Wien, wo es mit mehreren Personen der Hofgesellschaft und schließlich mit der Kaiserfamilie zusammentraf. Der geradezu triumphale Erfolg gab Überlegungen über eine grundsätzliche Neuorientierung Nahrung. Auf beides ist zurückzukommen, wenn die Ereignisse des Zeitraums am Leitfaden der Chronologie vergegenwärtigt werden.

Am 16. Oktober 1748 wurde Gottsched zum vierten Mal Rektor der Leipziger Universität. Das Ereignis wurde von verschiedenen Seiten beachtet. Christian Friedrich Wernicke aus Königsberg veröffentlichte ein Glückwunschgedicht im Namen der Freien Gesellschaft, auch Ernst Daniel Adami aus Landeshut gratulierte mit einer gedruckten Ode. Der Waldenburger Pfarrer Nicolaus Kelz bekundete ein halbes Jahr später zumindest seine dahingehende Absicht, aber die Pflichten des Amts hielten ihn nicht nur vom Versemachen ab, er blieb auch die Antwort auf einen Brief Gottscheds schuldig und begründete die Verzögerung mit eben dem Gedicht, das nicht zustandegekommen war. Andere Korrespondenten beglückwünschten Gottsched in ihren Briefen oder betonten, wie Jacob Brucker, ihn angesichts der Rektoratsbürde mit unnötigen Briefen verschonen zu wollen. Tatsächlich gab es offenbar einige besondere Herausforderungen, über die sich Gottsched in einem Brief an Cölestin Christian Flottwell geäußert haben muß, der daraufhin sein Bedauern aussprach, daß es „wider die Gewohnheit der stillen Leipziger sehr unruhig“ zugehe (Nr. 35). In den Briefen unseres Bandes kommen, vermutlich stellvertre- 
tend für weitere Unannehmlichkeiten, zwei Vorfälle zur Sprache, die vom Rektor Gottsched Engagement und Fingerspitzengefühl gefordert haben dürften. Sein Fakultätskollege Johann Rudolph Kiesling protestierte gegen juristische Angriffe, die eine Verletzung seiner professoralen Rechte darstellten. Er wollte sich deswegen „ad Serenissimum“ wenden. Die Universität sollte zuvor einen „allerunterthänigsten Bericht" nach Dresden schikken (Nr. 14). Tatsächlich war Kiesling hochverschuldet, in Dresden gingen deshalb Beschwerden ein, ${ }^{1}$ im Hause Gottsched hatte der Name Kiesling seit seinem Einschleichen in die Leipziger Universität keinen guten Ruf. ${ }^{2}$ Gleichwohl mußte Gottsched auf die Wahrung der Rechte des Professorenkollegen achten. Daß ihn die Angelegenheit und die familiäre Konstellation Kieslings beschäftigte, läßt sich an den Äußerungen ermessen, mit denen Korrespondenten auf seine nicht überlieferten Briefe reagierten. Im anderen Fall war das aggressive Verhalten eines Studenten angemessen zu ahnden. Studentische Regelverstöße waren eher Routinesachen, der konkrete Fall erforderte indes ein besonderes Vorgehen: Bei dem Studenten handelte es sich um den Sohn des Polizeidirektors der Französischen Kolonie in Berlin. Gottsched scheint dies genau registriert und in seinem Vorgehen berücksichtigt zu haben. Er nahm seinerseits mit dem Vater Jean Benjamin de Feriet Verbindung auf, wie aus dessen Antwortbrief entnommen werden kann. Der Vater befürwortete die Karzerstrafe, wollte aber größeres Aufsehen und langfristige nachteilige Wirkungen eines möglichen Urteils wegen Mordversuchs verhindern. Gottsched engagierte einen Anwalt seines Vertrauens, ein ehemaliges Mitglied seiner Rednergesellschaft wie später der Gesellschaft der freyen Künste. Dieser konnte das schlimmste verhindern, gemessen an der ursprünglichen Anklage fiel das Urteil glimpflich aus.

Eine besondere Beanspruchung ergab sich aus dem Tod Manteuffels, der nicht nur Gottsched persönlich, sondern die Universität insgesamt betraf. Manteuffel führte, seit er sich 1740 in der Stadt niedergelassen hatte, ein offenes Haus für Angehörige der Universität, die sich in schwierigen Situationen auf ihren ehemaligen Absolventen verlassen konnte. So war es nicht übertrieben, wenn Johann Friedrich Wilhelm Jerusalem die Folgen für die Leipziger Universität bedachte: „Und wo werden je die Wissenschaften einen solchen Beforderer, wo wird je die Vniversität Leipzig eine solche

${ }^{1}$ Vgl. Dresden, Hauptstaatsarchiv, 10088 Oberkonsistorium, Loc. 02128/01, Bl. 494v.

2 Vgl. unsere Ausgabe, Band 6, S. 625 f.; Band 7, S. 23, 50 f., 193, 214. 
Säule wiederfinden, die ihr beÿ der grösten Zierde zugleich die stärckste Stütze war“ (Nr. 97). Auch für Gottsched war der „beständige und unermüdete Fürspruch, womit der höchstsel. Graf die hiesige Universität, bey Sr. Königl. Majest. und allen Großen des Hofes unterstützet ", 3 in besonderer Weise erwähnenswert. Eine öffentliche Gedenkveranstaltung, wie sie reichlich zwanzig Jahre zuvor für die sächsische Kurfürstin in Leipzig anberaumt wurde, mußte sich die Universität versagen. Die „Circonstances de quelques Grands de la Cour ne permettent pas, que l'Université fasse quelque Solennité publique” (Nr. 62), schrieb Gottsched einigermaßen unbestimmt. Immerhin wurde im Professorenkonzil beschlossen, für den „Cabinets-Ministre“ Manteuffel „ein Carmen“ im Namen der Universität anzufertigen mit dem Zusatz, es solle „wegen Titulatur alle Vorsicht gebrauchet werden. “4 Man verzichtete auf die Bezeichnung Kabinettsminister, die noch auf dem Titel der 1743 veröffentlichten Beschreibung der akademischen Jubelfeyer zu finden ist. Wenn auch keine öffentliche Feier stattfand, so wurde an prominenter Stelle, in den Ansprachen anläßlich der Magisterpromotion im Februar 1749 und, soweit es Gottsched betraf, bei der Niederlegung des Rektorats an Manteuffels Verdienste um die Universität erinnert. In Gottscheds Wohnung versammelte sich die Nachmittägige Rednergesellschaft. In „Gegenwart, fast aller vornehmen Freunde und Verehrer des Hochseligen" 5 hielt der Student und späterhin namhafte Dichter Christian Felix Weiße eine Rede auf den Verstorbenen. Unverzüglich nahm Gottsched die Gestaltung einer Gedenkschrift in Angriff, die zur bevorstehenden Ostermesse erscheinen sollte. Die Manteuffel gewidmeten Passagen der genannten akademischen Ansprachen wurden dort ebenso aufgenommen wie Weißes Rede. Da Manteuffels Ansehen durch eine möglichst große und repräsentative Anzahl von Beiträgen dokumentiert werden sollte, lud Gottsched zur Mitarbeit ein. Die erwähnten Leipziger „vornehmen Freunde" lieferten bereitwillig lateinische und deutsche Gedichte für den Band. Christian Wolff beriet sich mit Gottsched, ob seine Würdigung als Beitrag für eine Publikation oder als spontane Äußerung in Briefform verfaßt sein sollte. Man entschied sich für letzteres, und Wolff, der mit Manteuffel persönlich bekannt war und seit Jahren einen inhaltsreichen und vertrauten Briefwechsel geführt hatte, hob Manteuffels Einsatz für

\footnotetext{
${ }^{3}$ Ehrenmaal Manteuffel (Mitchell Nr. 396), S. 14.

${ }^{4}$ Leipzig, Universitätsarchiv, Rep. I/XVI/1 40, Bl. 68r und v, Nr. 4.

5 Ehrenmaal Manteuffel, S. XII.
} 
seine, Wolffs, Rehabilitation am Berliner Hof hervor und betonte, daß Manteuffel gegen den modischen Trend Intellektualität und Religiosität auf vorbildliche Weise verbunden habe. Auch Jean Henri Samuel Formey und Jerusalem, deren Lebenskreise in den zurückliegenden Jahren zahlreiche Überschneidungen mit Manteuffel aufwiesen, reagierten sofort auf Gottscheds Aufruf. Die Hoffnung auf eine Resonanz von Mitgliedern der von Manteuffel ins Leben gerufenen Alethophilengesellschaft wurde hingegen enttäuscht. Die im Brief an Formey namentlich als Beiträger vorgesehenen Stettiner Alethophilen sind im Ehrenmaal nicht vertreten. Ähnlich erfolglos waren die Bemühungen in der Weißenfelser Sozietät, die als dritte nach Berlin und Leipzig entstanden war und sich mit großer Ernsthaftigkeit unter der Protektion Manteuffels konstituiert hatte. ${ }^{6}$ Nach der Auflösung des Weißenfelser Hofes im Jahr 1746 waren die Mitglieder allerdings in alle Winde zerstreut. Einzig Gottlob Carl Springsfeld war in Weißenfels verblieben. Er selbst sah sich zu einem Beitrag nicht in der Lage, versuchte aber, die ehemaligen Gesellschaftsgenossen zu bewegen, was nicht gelang. Die Geistlichen unter den Alethophilen wollten mit dem Namen Manteuffel mittlerweile nicht mehr in Verbindung gebracht werden, da er „des Naturalismi verdächtig" sei und in diesem Sinne, also gegen Kirche und Offenbarungsreligion, gewirkt habe. Unsachliche Verdächtigungen dieser Art wären an Manteuffel abgeprallt, für abhängige Amtsträger jedoch war es keine Empfehlung, mit einer solchen Gesinnung in Verbindung gebracht zu werden. Ablehnung erfuhr er nicht nur von den Geistlichen. „Die weltliche Bank unserer Gesellschaft denkt nicht viel besser“. Sie „spotten“ über den Plan einer Gedenkschrift „und erklären es für Schulfüchserey“ (Nr. 68). Offenbar fühlten sich die im praktischen Leben wirkenden ehemaligen Wahrheitsfreunde dem Gesellschaftswesen mit seiner philosophischen Prägung und einer gewissen Pedanterie entwachsen. Eine Person, die in Gottscheds Briefwechsel mit Manteuffel nirgendwo genannt ist, tritt bei der Vorbereitung des Ehrenmaals erstmals und nur hier in Erscheinung, der Dresdner Arzt Johann Christoph Neide. Gottsched kannte ihn nicht persönlich, die „allzu gute Meinung von meiner unbekanten Person“, die Neide in Gottscheds Brief wahrgenommen hatte, verdankte sich offenbar

${ }^{6}$ Vgl. Stefan Lorenz: Wolffianismus und Residenz. Beiträge zur Geschichte der Gesellschaft der Alethophilen in Weißenfels. In: Detlef Döring, Kurt Nowak (Hrsg.): Gelehrte Gesellschaften im mitteldeutschen Raum (1650-1820). Teil 3. Leipzig 2002, S. 113-144. 
der Fürsprache Manteuffels, der ihn auch gegenüber Christian Wolff als „Excellent Medecin et philosophe, et un des meilleurs amis que j'aie“ bezeichnet hatte. ${ }^{7}$ Neide und Manteuffel debattierten große Fragen, wie der Bericht über die philosophischen Unterredungen zu erkennen gibt, in denen, wie Neide einräumt, „paradoxa mit untergelauffen“ (Nr. 74), unkonventionelle Auffassungen also. Das betrifft beispielsweise die Annahme, daß Unterschiede in den Bedingungen der menschlichen Existenz aus dem Verhalten im vorherigen Leben resultieren. Diese Erklärung ist nur plausibel, wenn man von Reinkarnation und der Wanderung einer identischen Seele durch verschiedene Existenzen ausgeht, eine Auffassung, die nicht zum Repertoire christlicher Lehrmeinungen gehörte ${ }^{8}$ und bei einem wolffianischen Aufklärungsfreund wie Manteuffel überrascht.

Der von Gottsched in Aussicht gestellte Erscheinungstermin Ostermesse 1749 wurde nicht eingehalten. Infolge der Wienreise und ihrer Nachbereitung, derentwegen auch der Neue Büchersaal in der zweiten Jahreshälfte 1749 nicht erschien, gelangte die Gedenkschrift auf Manteuffel erst 1750 an die Öffentlichkeit.

Als Rektor war Gottsched für den Eintrag der Studienanfänger in die Rektormatrikel zuständig. Die Briefe erlauben Beobachtungen zur Immatrikulationspraxis. Die Korrespondenten empfahlen ihre Schützlinge nicht nur der besonderen Aufmerksamkeit Gottscheds. Er wurde vielmehr von verschiedenen Seiten ersucht, Immatrikulationen wegen der Bedürftigkeit angehender Studenten unentgeltlich vorzunehmen. Bittsteller waren Kollegen wie Paul Daniel Longolius und Johann Christian Hebenstreit, ehemalige Schüler wie Johann Friedrich Haas oder Personen, die durch das Amt mit Gottsched in Verbindung standen wie Andreas Erlmann. Die Betroffenen waren Schüler, Landsleute und Familienangehörige der Bittsteller oder, im Fall Joachim Lyons, ein Konvertit, der von seiner Familie oder der früheren religiösen Gemeinschaft keinerlei Unterstützung erwarten durfte und sich an den Theologieprofessor Hebenstreit gewandt hatte. Hebenstreit unterstützte das Gesuch und setzte sich beim Rektor für ihn ein. Da Gottsched mit eigener Hand eine Tabelle über die Immatrikulationen und alle damit verbundenen Aktionen während seines Rektorats angelegt

${ }^{7}$ Manteuffel an Wolff, Leipzig 25. Dezember 1747. In: Briefwechsel Wolff-Manteuffel 3, Nr. 409.

${ }^{8}$ Vgl. Helmut Zander: Geschichte der Seelenwanderung in Europa. Alternative religiöse Traditionen von der Antike bis heute. Darmstadt 1999, S. 299-321. 
hat, läßt sich feststellen, daß er die Bitten beherzigt, Gebühren erlassen und damit auf Einnahmen verzichtet hat.

Merkwürdig mutet die Unbekümmertheit an, mit der Gottsched für die Kinder seines Verwandten Carl Ludwig Rosner in Marienburg Bescheinigungen über die Deposition, das mit Kosten verbundene Aufnahmeritual in die Universität, ausstellte. Rosner hatte Gottsched im Oktober 1748 über seine familiäre Situation unterrichtet, neben drei Mädchen hatte er zwei Söhne, der jüngere war zu diesem Zeitpunkt ein halbes Jahr alt. Gottsched scheint daraufhin ungebeten Depositionsurkunden nach Marienburg geschickt zu haben, so daß Rosner schreiben konnte: „Vor die 2. Depositiones vor meine beÿde Jungens dancke ich dem $\mathrm{H}$. Vetter auf das verbindlichste". Allerdings handelte es sich um eine Art Blankoformular ohne detaillierte Angaben. Rosner teilte Gottsched Geburtsdaten und Vornamen der Knaben mit und bat um ein „Diploma“, das diese Angaben enthielt. Er werde dann "die alten, darinnen kein vornahme ist, zerreißen“" (Nr. 66). Gottsched hatte folglich ein amtliches Schreiben zugesandt, das den kleinen Knaben den Vollzug der Deposition attestierte und ihnen Umstände und Kosten ersparen sollte. Selbst die jungen Brüder von Rosners Frau, einer geborenen Pusch, wurden von Gottsched mit entsprechenden Zeugnissen ausgestattet. Allerdings wurde von den Dokumenten nicht in jedem Fall Gebrauch gemacht. Nur eine der genannten Personen, Abraham Pusch, nahm 1750 in Leipzig ein Studium auf. Neben dem Immatrikulationsdatum, 2. November 1750, ist die Deposition von 1749 vermerkt, ${ }^{9}$ zweifellos aufgrund von Gottscheds Bescheinigung. Dies trifft auch auf den jüngeren Bruder Samuel Gottwerth Pusch zu. Er ist in der Leipziger Matrikel nicht registriert, aber sein Eintrag in der Königsberger Matrikel vom 25. März 1754 enthält den Vermerk: „Lipsiae iam inscriptus“..10 Der Vermerk kann nur auf dem von Gottsched ausgestellten Dokument beruhen, denn anders als Rosner annahm, waren weder seine Söhne noch die Schwager im Leipziger „Albo Accademico“ (Nr. 200) eingetragen.

Anfang 1748 hatte die Universität das Privileg für die Veröffentlichung Leipziger Kalender erhalten. Die damit verbundene Hoffnung auf eine Aufbesserung der Universitätskasse erfüllte sich nicht, da die auswärtige Konkurrenz mit preiswerten Angeboten den Markt überschwemmte. Die Universität war einerseits an obrigkeitlichen Gegenmaßnahmen interes-

9 Vgl. Leipzig Matrikel, S. 48 (Busch).

10 Königsberg Matrikel, S. 457, Nr. 25. 
siert. Als Rektor war Gottsched mit der Angelegenheit befaßt, er wurde in diesem Sinne bei dem Präsidenten des Oberkonsistoriums Christian Gottlieb von Holtzendorff vorstellig, der sich zugunsten der Universität einzusetzen versprach. Andererseits wurde versucht, attraktive und schon in der Titelei augenfällige Gegenangebote auf dem Kalendermarkt vorzulegen. Auch hier mußte der Rektor aktiv werden. Gottsched hat mehrere Spezialkalender projektiert, wie die Briefe des ausführenden Kalendermachers August Gottlob Böhme zeigen. Möglicherweise besteht ein Zusammenhang zwischen den konzeptionellen Überlegungen zu Leipziger Kalendern, mit denen sich Gottsched qua Amt befassen mußte, und weiteren Publikationen bzw. Publikationsplänen, die das städtische und universitäre Leben dokumentieren sollten. Sie sind bedauerlicherweise kaum ausgeführt worden und kommen nur in einem Brief zur Sprache. Ebenfalls nur in einem Brief und eher zufällig erfährt man, daß Gottscheds Amtstätigkeit im Briefzeitraum nicht auf das Rektorat beschränkt war. Vom Mai 1748 an war er auch als Großprobst für die Verwaltung der drei alten Universitätsdörfer zuständig. Der Briefschreiber bescheinigte ihm „besondere Vorsorge das gute in hiesigen 3 Gemeinden zu befördern" (Nr. 64).

Kürzere Reisen ins Altenburger Land hatte das Ehepaar Gottsched schon mehrfach unternommen, wie umgekehrt auch Friedrich Heinrich von Sekkendorff mit Gefolge die Gottscheds besuchte. Seckendorff schrieb denn auch bei Gelegenheit, man werde sich im Sommer sehen. Nach dieser allgemein gehaltenen Einladung brachte Gottsched einen Besuch zur Feier der goldenen Hochzeit ins Spiel. Man war willkommen, und wie im Jahr zuvor rühmte Gottsched Seckendorffs Offenheit für Personen niedrigeren Standes, und wie im Jahr zuvor betonte Seckendorff, daß in seinem Verständnis der Adel einer Person durch ihre Tugend gewonnen werde. Schon als Knabe sei „Sola virtus nobilitat" sein Wahlspruch gewesen (Nr. 139). An den Besuch in Altenburg schloß sich ein kurzer Aufenthalt in Gera an. Das Ehepaar Gottsched stattete allen drei Geraer Korrespondenten Hausbesuche ab, alle bedauerten die Kürze des Aufenthalts und entschuldigten sich für die Dürftigkeit der Bewirtung.

Diese Reise war aber nur eine Art Vorspiel für einen ausgedehnten Auswärtsaufenthalt, der seit längerem erwogen worden war. Schon zu Anfang des Jahres 1748 hatte Luise Adelgunde Victorie Gottsched ihren Schwager Johann Heinrich Gottsched informiert: „Vielleicht wird künftiges Jahr eine Reise ins Carlsbad unternommen. Die Aerzte sagen, daß dieser Heilbrunnen auch meine Hypochondrie heilen würde, ich wünschte es, und 
werde alles darzu beytragen, was zur Cur erfordert wird“ (Band 13, S. 4). Im Januar 1749 hatte der Plan verbindlichere Formen angenommen. Christian Clodius schrieb aus Zwickau: „Ich wünsche daß Ew. HochEdelgeb. den nächsten Sommer genöthiget werden, den nächsten Weg, durch Zwikau, ins Carls Bad zu reisen“" (Nr. 48). Spätestens bei den frühsommerlichen Besuchen in Gera war der Kuraufenthalt fest eingeplant. Heyde wünschte „eine glückliche Reise nach dem Carlsbade“ (Nr. 144). Die erforderliche Reiseerlaubnis wurde Gottsched merkwürdigerweise von Engelbert Heinrich Schwartze übersandt. Offenbar hatte Gottsched Schwartze, den Juristen und Gerichtshalter Heinrich von Bünaus, mit der Abwicklung der Antragsformalitäten für die „Badecur“ beauftragt. Die behördliche Genehmigung ist in einem Aktenband verzeichnet, in dem die ausgegangenen Reskripte an verschiedene Einrichtungen protokolliert sind. Im Namen des Königs wurde am 7. Juli 1749 die Universität darüber informiert, daß Gottscheds „gehorsamstes ansuchen gnädigst bewilliget, daß derselbe seiner Gesundheit halber, auff einige Wochen ins Carls Bad verreisen möge; und begehren demnach hierdurch, ihr wollet ihn deßen, auch daß er sich zu rechter Zeit wieder einfinden solle, bedeuten ". ${ }^{11}$ Von einer Reise nach Wien findet sich nicht einmal eine Andeutung, obwohl das Reiseziel Wien bereits fixiert war. Seit wann sich Gottsched mit dem Gedanken getragen hatte, wird nicht herauszufinden sein. Aber schon Anfang Mai hatte er seine Absicht gegenüber Franz Christoph von Scheyb bekundet, der am 18. Juni daran erinnerte, daß ihm Gottsched dies „vor 6 wochen" im Vertrauen mitgeteilt und er das "geheimnis“ bewahrt habe (Nr. 147). Infolgedessen war er darüber verwundert, von einer dritten Person auf den Besuch angesprochen worden zu sein. Gottsched hatte offenbar auch weitere Wiener Korrespondenten informiert, die ihrerseits die Nachricht von Gottscheds bevorstehender Reise verbreiteten, so daß Christian Wolff aus Halle am 11. Juli mitteilen konnte: „Man schrieb mir aus Wien, daß Sie ins Carlsbad, und von dar nach Wien kommen würden“ (Nr. 165). Am 12. Juli versicherte Scheyb: „Alle liebhaber der deutschen gelehrsamkeit erfreuen sich auf Dero Ankunfft" (Nr. 166). Der engere, Gottsched bald amtlich, bald mäzenatisch verbundene Personenkreis war zu diesem Zeitpunkt, soweit es sich anhand von Briefen feststellen läßt, noch keineswegs im Bild. Erst von Karlsbad aus informierte Gottsched

${ }^{11}$ Dresden, Hauptstaatsarchiv, 10088 Oberkonsistorium, Loc. 02128/01, Bl. 509v. 
seine Patrone Joseph Anton von Wackerbarth und Seckendorff, am 15. bzw. 22. August. Immerhin scheint Wien gegenüber Seckendorff schon ins Gespräch gebracht worden zu sein. Ihren Bericht über die Reise eröffnete Frau Gottsched mit den Worten: „Ew. Excellenz habe ich vor meiner Abreise ins Carlsbad gestanden, wie sehr ich wünschte, das glänzende Wien zu besuchen und die Monarchin zu sehen". ${ }^{12}$ Eine Absichtserklärung klingt anders. Gottscheds Mitteilung über sein Vorhaben, nach Wien zu reisen, knüpft jedenfalls nicht an eine vorhergehende Erörterung an, und wenn sie erfolgt wäre, hätte er die Bitte um Empfehlungsbriefe nicht erst im Zusammenhang mit dieser Mitteilung anbringen müssen. Diese Geheimniskrämerei ist merkwürdig und wirft die Frage nach Gründen und nach den Absichten auf, die mit dem Wienaufenthalt verbunden waren. Gegenüber Seckendorff und Wackerbarth verwies Gottsched auf den Besuch der kaiserlichen Bibliothek als Zweck seiner Reise. Auch im Sendschreiben an Scheyb wird der Bibliotheksbesuch an prominenter Stelle genannt, in weiteren öffentlichen Verlautbarungen ebenso. Über Gottscheds Interesse an älteren poetischen Texten war die Öffentlichkeit, war auch der Hof in Dresden informiert, mit dessen Hilfe Gottsched zwei Jahre zuvor seine Anfrage in Paris anbringen konnte (Band 12, S. XIII). Forschungen in der Bibliothek wären vor diesem Hintergrund ein plausibles Ziel gewesen, das keiner Geheimhaltung bedurft hätte. Erinnert man sich aber, wie Gottsched im Jahr zuvor sein Interesse an einer Professorenstelle in Halle ausgerechnet vor Manteuffel, seinem entschiedensten Förderer und Vertrauten, verbergen wollte (Band 13, S. XXVII), stellt sich die Vermutung ein, es könnten auch hier weiterreichende Interessen und der Gedanke an Wien als Wirkungsort sein Versteckspiel verursacht haben. Die Erfolge des Sterbenden Cato und der Zuspruch, den Gottsched im Laufe des Jahres 1748 in mehreren Briefen aus Wien erhalten hatte, können derartige Überlegungen angeregt oder bestärkt haben. Wackerbarth brachte es unumwunden zur Sprache: Er wünschte Gottsched Erfolg, sähe es aber nicht gern, wenn Gottsched Lust auf die Trennung von den Leipziger Musen überkomme. Ältere Biographen gehen ganz selbstverständlich davon aus, daß Gottsched mit der Reise große Pläne verband. „Nicht weniger als Durchsetzung der Gemeinsprache vermittelst kaiserlichen Machtspruches wird es gewesen

${ }^{12}$ L. A. V. Gottsched an Friedrich Heinrich von Seckendorff, Oktober 1749. In: Runckel 2, S. 16-23, 16. 
sein."13 Die Autoren führen alle mit Wien in Verbindungen stehenden Äußerungen früherer Korrespondenzen an und sehen das Wienunternehmen des Jahres 1749 als logische Konsequenz. Aber man darf nicht vergessen: Trotz aller Beifallserklärungen waren Gottscheds Kontakte nach Wien eher bescheiden. Nicht ohne Grund bat er Seckendorff und Wackerbarth um Empfehlungsbriefe an adlige Häuser, da er „wenig Bekanntschaft daselbst habe" (Nr. 186). Was die Kaiserfamilie angeht: Gottsched wünschte sie, wie es im Sendschreiben an Scheyb heißt, „Bewundernd anzusehn“ (Nr. 189). Daß es zu einer persönlichen Begegnung mit dem Kaiserpaar kommen würde, dürfte Gottsched in seinen kühnsten Träumen nicht geahnt haben. Mit aller gebotenen Vorsicht kann man festhalten: Primäres und offizielles Reiseziel waren Bibliotheksstudien. Darüber hinaus war man an Kontakten interessiert und bereit, den Kairos zu nutzen. Das Ehepaar trat die Reise zu Beginn der Hundstage an, also im letzten Viertel des Monats Juli. Dies ist aus Gottscheds Reisebericht zu erfahren, dem auch die folgenden Angaben entnommen sind. ${ }^{14} \mathrm{Er}$ ist allerdings in lateinischer Sprache und als akademische Einladungsschrift veröffentlicht, was Auswirkungen auf den Inhalt hatte: Es werden bevorzugt gelehrt-literarische Belange mitgeteilt; daß Gottsched in Begleitung seiner Gemahlin reiste, wird fast völlig unterschlagen. Die erste Station der Reise war Altenburg, wo Begegnungen mit Salomon Ranisch, Johann Christian Stemler und dem Altenburger Kanzler Ernst Friedrich von Seckendorff zustandekamen, um nur die uns bekannten Korrespondenten Gottscheds zu nennen. In Zwik-

13 Eugen Wolff: Gottscheds Stellung im deutschen Bildungsleben. Band 1. Kiel; Leipzig 1895, S. 41. Nach Reichel unternahm Gottsched die Reise, um „bei den Majestäten seine ganze persönliche Kraft für die große vaterländische Sache einzusetzen." Eugen Reichel: Gottsched. Band 2. Berlin 1912, S. 724. Auch nach Danzel wollte Gottsched „unter der Autorität seiner allerhöchsten römisch kaiserlichen Majestät sein Reformationswerk betreiben“. Theodor Wilhelm Danzel: Gottsched und seine Zeit. Auszüge aus seinem Briefwechsel. Leipzig 1848, S. 290.

14 Gottsched: Ad Capessendos Honores ... Invitat Et Aliquam Nuperi Itineris Sui Rationem Reddit. Leipzig: Breitkopf, 1749 (Mitchell Nr. 388). Eine Neuausgabe dieses Textes und der als Rede vorgetragenen Singularia Vindobonensia (Breitkopf, 1750, Mitchell Nr. 427) mit deutscher Übersetzung und ausführlicher Erläuterung der von Gottsched erwähnten Personen, Orte und Institutionen sowie einer Erörterung der akademischen Textgattungen bietet Anna Maria Lesigang-Bruckmüller: Eine oratio academica als Reisebericht? Johann Christoph Gottscheds Reise nach Wien im Spiegel seiner Universitätsrede Singularia Vindobonensia. Wien, Institut für Klassische Philologie, Dissertation, 2017, http://othes.univie.ac.at/51135/1/48897.pdf. 
kau traf Gottsched auf seinen alten Freund Christian Clodius, den Rektor der Ratsschule. Die Bestände der Ratsschulbibliothek waren Gegenstand ihres Briefwechsels, bei ihrer Besichtigung entdeckte Gottsched rare Drucke und wertvolle Handschriften. Die Sichtung nahm einige Zeit in Anspruch, immerhin wurden drei Tage in Zwickau verbracht. ${ }^{15}$ Der anschließende Kuraufenthalt in Karlsbad, das vordergründige Ziel der Reise, war von Gottlob Carl Springsfeld vorbereitet worden. In einem Brief informierte er über die Herberge, nannte die Preise und erwähnte „zweÿ besondere Kammern für die Bedienung " (Nr. 175), über die in Gottscheds Reisebericht und in den Briefen kein Wort verloren wird. Springsfeld hoffte, das Ehepaar noch vor seiner Abreise am 2. August in Karlsbad begrüßen zu können. Tatsächlich scheinen die Gottscheds bereits Ende Juli in Karlsbad eingetroffen zu sein, denn Ernst Friedrich von Seckendorff bezieht sich am 8. August auf einen nicht überlieferten Brief Gottscheds vom 1. des Monats, in dem sich Gottsched augenscheinlich schon über die „Gesellschaft im Carlsbade“ (Nr. 186) geäußert hat, was erste Erfahrungen voraussetzt. Über den medizinischen Gewinn der Kur und die Ärzte, die „bey nahe das Athemholen verbiethen“ (Nr. 186), äußerte sich Gottsched eher belustigt. Er hatte Unmengen von Brunnenwasser einzunehmen: „Wohl dreyßig Bächer voll verschluck ich jeden Morgen,/ Wie nöthig sie mir sind, laß ich den Arzt besorgen“ (Nr. 189). Der intellektuelle Gewinn des Aufenthalts hielt sich in Grenzen. Gottsched vertrieb sich die Zeit mit der Anfertigung von Gedichten. So entstand das in unserem Band als Brief an Scheyb gedruckte Sendschreiben an einen Vornehmen von Adel, in dem er seine Vorfreude auf Wien zum Ausdruck brachte, und die Ode Das Carlsbad mit Naturbeobachtungen, Ausführungen zur heißen Quelle und ihren Wirkungen und Urteilen über die Kurgesellschaft, „Der Lüste Tummelplatz“. ${ }^{16}$ Beide Gedichte enthalten euphorische Passagen über die Kaiserin, ihr weises Regierungshandeln und die Vorzüge der kaiserlichen Familie. Thematisch paßte dies nicht unbedingt zu den Texten, als Empfehlung für den Autor war es hingegen von Wert, der denn auch für die rechtzeitige Publikation

15 Einträge in den Benutzerbüchern belegen die Konzentration auf Bibliotheksstudien, es heißt zu Gottsched: „blieb 3 gantze Tage auf d. Bibliotheck, und suchte alte teutsche, sonderl. Com. u. Theatr. Schr.“ Zwickau, Ratsschulbibliothek, Ms 43.1.21, Bl. 7r.; ähnlich Ms. 172.11, Bl. [1r].

16 Gottsched: Das Carlsbad, In einer Ode besungen. Regensburg: Gebrüder Zunkel, 1749 (Mitchell Nr. 389), Bl. [**4r]. 
der Verse sorgte. Die Kur war am 26. August beendet, als nächste größere Station war Nürnberg vorgesehen. Auf dem Reiseweg besuchte die Gesellschaft in Bayreuth Schloß, Opernhaus und Naturaliensammlung, in Erlangen traf man auf alte Bekannte und Korrespondenten, die vom Erscheinen Gottscheds überrascht waren. ${ }^{17}$ Offenbar war keiner von seinen Korrespondenten über die Reise im Bilde, und Gottsched scheint auch das Ziel seiner Reise in Nebel gehüllt zu haben. Anders ist es kaum zu erklären, daß Georg Wilhelm Pötzinger, bei dem Gottsched in Erlangen tafelte, am 18. September schrieb, Gottsched werde wohl nach dem Besuch der „Böhmischen Gegenden“ in Leipzig „angekommen seÿn“ (Nr. 202). Über einen Mangel an Aufmerksamkeit konnten sich die Gottscheds in Erlangen nicht beklagen. Anders als im akademischen Reisebericht erwähnt Gottsched in der Lebensbeschreibung seiner Frau auch die ihr erwiesene Aufmerksamkeit während einer Disputation in der Erlanger Universität. ${ }^{18}$ In Nürnberg war die Gastgeberin Maria Regina Thomasius vorbereitet, sie hatte sich den Besuch des Ehepaares ausgebeten. ${ }^{19}$ Gottsched studierte Handschriften und Bücher in der Bibliothek ihres verstorbenen Vaters, aus der er bereits Handschriften erworben hatte, und fand Zugang zu weiteren Bibliotheken und Sehenswürdigkeiten der Stadt. Frau Gottsched erkor Maria Regina Thomasius zur Herzensfreundin, wovon noch zu berichten ist. Über den weiteren Reiseverlauf informieren die Briefe der Gottschedin an Frau Thomasius. Sie erwähnt die von „Klippen, Steinen und Abgründen“ (Nr. 196a) geprägte beschwerliche Reise nach Regensburg. Gottsched fühlte sich von der unwirtlichen Gegend und ihren Bewohnern derart insultiert, daß er sich mit der Ode Die Oberpfalz ${ }^{20}$ rächte, was wiederum Verteidiger der Pfalz auf den Plan rief. ${ }^{21}$ Man traf am 5. September in Regensburg ein. Es gab Bibliotheksbesuche und Begegnungen mit Diplomaten,

17 „Hi tanquam coelo delapsum me mirantes ...“; Gottsched nannte namentlich die Korrespondenten Caspar Jacob Huth, Johann Heinrich Meister (Lemaitre), Samuel Wilhelm Oetter und Georg Wilhelm Pötzinger; vgl. Gottsched: Ad Capessendos Honores ... Invitat Et Aliquam Nuperi Itineris Sui Rationem Reddit (Anm. 14), S. 8.

18 Vgl. Gottsched, Leben der Gottschedin, S. 545.

19 Vgl. Gottsched, Leben der Gottschedin, S. 544.

20 In: Gottsched: Neueste Gedichte auf verschiedene Vorfälle. Regensburg: Gebrüder Zunkel, 1749; Mitchell Nr. 390.

${ }^{21}$ Vgl. Manfred Knedlik: Gegen-Bilder. Zum oberpfälzischen Literaturstreit im Jahr 1750. In: Die Oberpfalz - Land der Pfalzgrafen in der Mitte Europas. Festschrift zum 35. Bayerischen Nordgautag in Vohenstrauß. Regensburg 2004, S. 203-208. 
die Gottsched aus ihrer Studienzeit kannte. Ein Treffen mit seinem vertrauten Korrespondenten Jacob Brucker unterblieb, weil Gottsched auch ihn vorab nicht informiert hatte. Eine kurzfristig anberaumte Zusammenkunft in Regensburg ließen Bruckers Amtsgeschäfte nicht zu, und Bruckers Vorschlag zur Änderung der Reiseroute wurde von Gottsched ignoriert. Am 7. September, einem Sonntag, legte das Schiff in der Morgenstunde in Richtung Wien ab. Die Kabinengesellschaft, von der die Gottschedin während der Wasserfahrt berichtete, war für das kinderlose protestantische Gelehrtenehepaar sicherlich eine Herausforderung.

Am 12. September kam man in Wien an. Für die Unterkunft war längst gesorgt, das Ehepaar erhielt „ein Freybillet zu den öffentlichen Schauspielen, für die ganze Zeit unsers Daseyns",22 es folgten Besuche in Bibliotheken, wissenschaftlichen Einrichtungen und Einladungen in vornehme $\mathrm{Fa}$ milien. Gottsched zählt die Namen auf, ohne ins Detail zu gehen. Seine Oratio Singularia Vindobonensia enthält den ausführlichsten Bericht über den Aufenthalt in Wien. Die Ereignisse werden auch in der Lebensbeschreibung seiner Frau rekapituliert, in der mit dem Brief an Frau Thomasius das Dokument abgedruckt ist, das einen unmittelbaren authentischen Erlebnisbericht enthält. ${ }^{23}$

Höhepunkt des Aufenthalts und der gesamten Reise, Zentrum auch der Berichte, war die persönliche Audienz bei der kaiserlichen Familie. Daß eine derartige Begegnung stattfinden würde, war nicht vorauszusehen, auch am Tage selbst, am 28. September 1749, nicht. Man war darauf eingestellt, ,in der großen Antichambre der Kaiserinn, mit 100 andern Personen zugleich die Hand küssen" zu dürfen. Daß man schließlich separat in einem kleinen Raum dem kaiserlichen Ehepaar unter allmählicher Hinzuziehung der Kinderschar begegnen, Gottsched als „Meister der deutschen Sprache" und Frau Gottsched als "gelehrteste Frau von Deutschland“ angesprochen und eine Konversation teilweise sehr persönlicher Natur von mehr als 30 Minuten führen würde, übertraf alle Erwartungen. Nach der Verabschiedung wurde das Ehepaar durch ,alle Kaiserl. Zimmer geführet, welches eine außerordentliche Gnade ist, die dem 1000ten Fremden nicht

22 Vgl. L. A. V. Gottsched an Friedrich Heinrich von Seckendorff, Oktober 1749. In: Runckel 2, S. 16-23, 19.

${ }^{23}$ Vgl. Gottsched, Leben der Gottschedin, S. 543-554; vgl. darüber hinaus L. A. V. Gottsched an Friedrich Heinrich von Seckendorff, Oktober 1749. In: Runckel 2, S. $16-23$. 
geschieht" (Nr. 207). Ob dieses auch von Gottsched geteilte Urteil ${ }^{24}$ über die Einzigartigkeit des Ereignisses richtig ist oder nicht vielmehr ein Mißverständnis, ${ }^{25}$ sei dahingestellt. Die Gottscheds waren überwältigt, nach Gottscheds Mitteilung wurden sie in "ganz Wien ... wie ein Wunder" angesehen. ${ }^{26}$ Sie sorgten dafür, daß dem Ereignis im Reich die nötige Aufmerksamkeit zuteil wurde, und in weiteren Gedichten wurde die kaiserliche Familie und ihre außerordentliche Erscheinung gefeiert.

Eine Steigerung war nach der Audienz nicht mehr möglich. Gottsched hätte Grund zur Abreise gehabt, da er „biß Michaelis zu Hauße“ (Nr. 194) sein mußte, wie er gegenüber Brucker seine Eile begründete. Da sich aber die Chance bot, ein weiteres Mal vor den Hoheiten zu erscheinen, wurde die Abreise, „bis auf diesen Punkt verschoben“27: Schon Anfang 1748 hatte Gottsched den Plan gefaßt, die Histoire de l'Académie royale des inscriptions et belles lettres ins Deutsche zu übersetzen. Dies erfährt man aus einer im Juli 1749 doppelt plazierten Nachricht, mit der Gottsched einer in Erfurt erscheinenden Übersetzung desselben Werks entgegentrat: „Unser berühmter Herr Professor Gottsched hat bereits vor anderthalb Jahren auf die Deutsche Uebersetzung der Histoire und Memoires der Königlichen Akademie der schönen Wissenschaften zu Paris, welche er allhier ans Licht stellen wollen, ein allergnädigstes Königl. Pohlnisches und Churfürstl. Sächsisches Privilegium erhalten, solches auch, nach Gewohnheit, an der Ostermesse 1748 allen hier anwesenden Buchhändlern bekannt machen und insinuiren lassen. "28 Im März 1749 wurde die Öffentlichkeit von der Übersetzung, von der einige Stücke bereits im Neuen Büchersaal erschienen waren, und der geplanten Erscheinungsweise unterrichtet. ${ }^{29}$ Die Vorrede, auf deren Inhalt bei dieser Gelegenheit schon hingewiesen wurde, konnte Gottsched mit Datum vom 12. August in Karlsbad abschließen und nach Leipzig senden. Johann Joachim Schwabe nahm in Leipzig noch einige Nachbesserungen vor, bevor

\footnotetext{
24 „Ex eruditorum autem ordine, qui propius admissi, vel per dimidiae spatium horae, cum Iisdem versati fuerunt, ego quidem novi neminem“. Gottsched: Singularia Vindobonensia. Leipzig: Breitkopf, 1750, S. XXIII.

25 Vgl. Barbara Stollberg-Rilinger: Maria Theresia. Die Kaiserin in ihrer Zeit. München 2017, S. 325.

26 Gottsched, Leben der Gottschedin, S. 553.

27 Gottsched, Leben der Gottschedin, S. 553.

${ }^{28}$ Neue Zeitungen 1749 (Nr. 61 vom 31. Juli), S. 542-544, Zitat S. 542; weitgehend wortgleich in: Neuer Büchersaal 8/6 (1749), S. $567 \mathrm{f}$.

${ }^{29}$ Vgl. Neuer Büchersaal 8/3 (1749), S. 252-281, 261.
} 
der Text zum Druck gelangte. ${ }^{30}$ Bei gleicher Gelegenheit muß auch der Text der Widmung an „Frau Marien Theresien, Römischen Kaiserinn“ nach Leipzig überschickt worden sein. Er ist in römischer Seitenzählung der Vorrede unmittelbar vorangestellt und trägt das Datum „Kaiser Karls Bad in Böhmen, Im August 1749“. ${ }^{31}$ Mit der Widmung ging Gottsched ein Risiko ein, denn eine ohne Genehmigung des Empfängers gedruckte Widmung barg die Gefahr der Mißbilligung. Wollte er aber erst eine Erlaubnis einholen, wäre die Übergabe während des Wienaufenthalts unmöglich gewesen. Gottscheds Rechnung ging auf. Die Widmung wurde genehmigt. Der fertige Druck kam noch rechtzeitig an, und Gottsched konnte das Werk höchstpersönlich dem Kaiser übergeben. Es wurde huldvoll aufgenommen, und am Abend dieses Tags erfolgte die Abreise. 32

Will man eine knappe Bilanz der Reise ziehen, so bleibt festzuhalten, daß Gottsched trotz der Audienz und weiterer gesellschaftlicher Ereignisse, die die Berichterstattung dominieren, das Ziel der Erschließung deutscher poetischer Texte nicht aus den Augen verloren hat. Schon während der Reise standen die Aufenthalte in Zwickau, Nürnberg und Regensburg und manche Unterredungen im Zeichen dieser Forschungen. In Wien war es neben der Universitäts- und Stadtbibliothek vor allem die Hofbibliothek, die er nach Möglichkeit täglich aufsuchte. Auch adlige Privatbibliotheken waren für ihn zugänglich, schließlich besuchte er, vermittelt und begleitet von Friedrich Wilhelm Weiskern, die Bibliothek des Stifts Klosterneuburg, wo er zuvorkommend empfangen wurde. Auch seine Frau war willkommen. Die Regeln verwehrten ihr den Zugang in die Klausur, aber der Dechant stellte ein annehmbares Alternativprogramm in Aussicht.

Unter Gottscheds Veröffentlichungen unseres Zeitraums bildet die vor der Abreise übergebene Übersetzung der Akademiegeschichte den Ab-

${ }^{30}$ Vgl. Geschichte der königlichen Akademie der schönen Wissenschaften zu Paris. Band 1. Leipzig: Johann Paul Kraus, 1749, S. XXXIV und unsere Ausgabe, Band 14, Nr. 189.

31 Vgl. Geschichte der königlichen Akademie (Anm. 30), S. [III]-XVII, Zitate S. [III] und XVII.

32 Abreisetermin war der 6. Oktober. Gottscheds auf diesen Tag datierter Brief an Francesco Maria Zanotti (Bologna, Accademia delle scienze, Tit. III. L.R.2 Antica Accademia) wurde noch von Wien aus versandt. Franz Christoph von Scheybs Abschiedsklage ist mit einer Datumsangabe versehen: Beurlaubung der deutschen Musen zu Wien, an den Herrn Professor Gottsched, bey seiner Abreise von Wien den 6. Octobr. 1749 (Leipzig, UB, 0342 XIV, Bl. 310-315). 
schluß. Am Anfang steht die Erstausgabe der Sprachkunst. Genau genommen wurde sie unmittelbar zuvor, zur Michaelismesse 1748, veröffentlicht, aber die beifälligen bis enthusiastischen Reaktionen darauf können in den Briefen dieses Bandes verfolgt werden. Das Werk war ein Verkaufserfolg. In Königsberg waren „50 St. in 8 Tagen abgegangen, daß keine mehr zu erhalten" (Nr. 46) war. Auch aus Wien ist zu vernehmen, daß die Sprachkunst „haufenweiß abgehe“ (Nr. 50). In Augsburg haben das Buch, so Jacob Brucker, „selbst einige unserer Regenten gelesen“ (Nr. 93). Im Februar 1749 war die Auflage vergriffen. Die Deutschen Gesellschaften in Königsberg und Göttingen, denen die Sprachkunst gewidmet war, lasen und besprachen sie in den Sitzungen gemeinsam oder hatten es zumindest vor. Flottwell schrieb Mitte Mai 1749, man sei „bis in die Helfte gekommen“ (Nr. 123), was er im September wiederholte. Rudolf Wedekind kündigte die gemeinsame Lesung in Göttingen an und schrieb auf Anraten des Präsidenten der Göttinger Deutschen Gesellschaft eine Rezension dieses „volkommenen libri classici“ (Nr. 11). Er legte sie seinem Brief zur Kenntnisnahme des Originaltextes bei, da er befürchtete, daß Albrecht Haller als Herausgeber der Göttingischen Zeitungen Eingriffe vornehmen könnte, was sich als nur zu berechtigt erwies. Die Hallersche Version mit ihren vor allem kritischen Bemerkungen stach unter den weithin positiven Beurteilungen der Sprachkunst hervor. In Briefen an Gottsched wurde sie mißbilligt. Zwei Passagen der Sprachkunst wurden von den Korrespondenten in besonderer Weise angesprochen. In einem ausgedehnten historischen Exkurs der Vorrede hatte sich Gottsched mit der jüngst von einem fränkischen Autor vorgetragenen Auffassung auseinandergesetzt, daß ein reines Deutsch nur in einer einzigen Region zu finden sei. In einer Grundsatzbetrachtung des Verhältnisses von Zentrum und Peripherie für die Sprachformung führte Gottsched zahllose antike und neuzeitliche Dichter an, die aus entlegenen Gegenden des jeweiligen Sprachraums stammten und dennoch einen mustergültigen Beitrag zur Hochsprache geleistet haben. Unter den Zeitgenossen waren es nicht zuletzt Korrespondenten, mit deren Nennung Gottsched seine Auffassung belegen wollte, daß sich die Konstitution und Pflege der deutschen Sprache den Beiträgen aus unterschiedlichen Regionen verdankt. Für Schlesien wurden beispielsweise Abraham Gottlob Rosenberg, Adam Bernhard Pantke und Christian Gottlob Stöckel, für Sachsen Johann Gottfried Hermann und Johann Christian Stemler angeführt, um nur einige zu nennen. Auch an Jacob Brucker und „dem trefflichen wienerischen Dichter, Herrn von Scheyb“ zeige sich, „daß Gelehrte aus al- 
len Landschaften, die sich mit Fleiß auf ihre Muttersprache legen, es in derselben weit bringen können" 33 . Die Betroffen waren überrascht über „dergleichen unvermuthete Ehre“ (Nr. 95) und den „unverdienten Platz in der Reihe ansehnlicher geistlicher Redner" (Nr. 188). Rosenberg erklärte, daß in ihm „eine Röthe aufstieg“ (Nr. 101), Scheyb war zugleich in seiner Eigenliebe geschmeichelt und in Schrecken versetzt, da er ungute Reaktionen seiner Landsleute befürchtete. Mit seinen Ausführungen verpflichtete Gottsched indes nicht nur seine Sympathisanten. Da er unter den Schweizer Beiträgern zur Hochsprache neben Johann Jacob Spreng und Johann Georg Altmann auch den „Herrn Hofrath Haller aus Bern“ 34 anführte, hatte er sich dem möglichen Vorwurf entzogen, nur Autoren seiner eigenen Geschmacksrichtung zu nennen. Als Herausforderung sahen Gottscheds Korrespondenten die in Widmung und Vorrede plazierte Aufforderung an, die Sprachkunst kritisch zu lesen und dem Verfasser Korrekturen und Ergänzungen mitzuteilen. Wie ernst dies Gottsched war, läßt sich nicht zweifelsfrei beurteilen. Die Korrespondenten sahen sich jedenfalls in die Pflicht genommen und zeigten so, daß sie sich als die von Gottsched aufgerufenen „Liebhaber unserer Muttersprache“ 35 verstanden. Flottwell kündigte an, seine „Zweifel beÿ einigen Abweichungen der Zeitwörter in unserem Lande" (Nr. 4) mitzuteilen. Rosenberg sprach sich für Teilungszeichen in zusammengesetzten Wörtern aus, da speziell dem Ausländer das Lesen von Wörtern wie Eheideen oder Gehörnerven beschwerlich sei. Zusätzlich interessierte er sich für das „Decliniren der alten Römischen Nahmen im Deutschen“ (Nr. 101). Johann Matthias Gesner, der Präsident der Göttinger Deutschen Gesellschaft, sandte seine Annotationen. Auch Jacob Brukkers Reaktion brachte zumindest die prinzipielle Bereitschaft zur Mitwirkung zum Ausdruck: „Ich weiß nichts daran zuverbeßern, so mir aber einiger Zusaz beyfallen sollte, will ich ihn zur Prüfung gerne übersenden" (Nr. 93). Daß Gottsched von dem Eifer, Defizite aufzuspüren, auch irritiert werden konnte, läßt sich an einer Richtigstellung Rudolf Wedekinds

33 Gottsched, Sprachkunst, Bl. [**8r]; AW 8/3, S. 23-27, 26. Diese Ausführungen sind nur in den ersten beiden Ausgaben der Sprachkunst enthalten. Dem Text der Ausgewählten Werke liegt die 5. Auflage zugrunde, in der die Vorrede zur ersten Ausgabe nur in reduzierter Form enthalten war. Folglich ist der entsprechende Abschnitt in den Ausgewählten Werken nur als Textvariante gedruckt und nicht erläutert. Die Namen werden im Register nicht aufgeführt.

${ }^{34}$ Gottsched, Sprachkunst, Bl. [**8r]; AW 8/3, S. 26.

35 Gottsched, Sprachkunst, Bl. ${ }^{* *} 3 \mathrm{v}$; AW 8/1, S. 13. 
beobachten. Der Göttinger hatte in Aussicht gestellt, „daß unsere Geselschaft sich gelegentl. die Freiheit nimt, Ew. Wolgeb. ihre Anmerkungen darüber mitzuteilen" (Nr. 11). Sein nächster Brief reagierte auf Befürchtungen, die die Ankündigung bei Gottsched ausgelöst hatte: „Unsere Absicht ist nicht, Dieselben zu widerlegen, oder unsere Anmerkungen im Drucke mitzuteilen, sondern Dero Grammatik gelegentl. in der D. G. durchzugehen, und unsere Noten Ew. Mgf. demnächst geschrieben mitzuteilen, damit Sie bei der neuen Auflage, die vermuhtl. bald erfordert werden wird, vielleicht beliebigen Gebrauch davon machen könten. Dis haben Sich Dieselben in der Vorrede ia selbst ausgebeten. Es seÿ ferne von uns, Sie zu widerlegen!“ (Nr. 44). Schon in der 1749 erschienenen zweiten Auflage der Sprachkunst wurden die Einsendungen teilweise berücksichtigt.

Auf Gottscheds während der Reise veröffentlichte Gedichte und ihre Folgen wurde bereits hingewiesen. Das Kalkül und die Wirkung, die der Gelegenheitspoesie zugrundeliegen konnten, lassen sich an einem weiteren Text aus unserem Zeitraum illustrieren: Nachdem die sächsische Kurprinzessin Maria Antonia Walpurgis Verse auf ihren Schwiegervater, den polnischen König, verfaßt hatte, wurde sie von der römisches Accademia dell'Arcadia im Sommer 1747 zum Mitglied erklärt. Gottsched erfuhr davon spätestens im Dezember 1747, als Wackerbarth den von Johann Adolph Hasse vertonten Text übersandte (Band 12, S. 526). Er ließ sich zu einem Gedicht inspirieren, dessen Entstehungszeit indes schwer zu bestimmen ist. Der Separatdruck erschien ohne Angaben zu Ort und Jahr. Ihre Wirkung entfalteten die Verse jedenfalls erst im Mai 1749, als Gottsched die Gelegenheit zu Präsentation und Repräsentation geschickt nutzte und das Gedicht als Medium verwendete, um eine bereits bestehende Verbindung zur Kurprinzessin und ihrem Ehemann noch zu verstärken. Schon im Oktober 1747 hatte Gottsched mit einer Rede in der Leipziger Universitätskirche vor dem Kurprinzenehepaar geglänzt. 1748 widmete er nach sorgfältiger Absprache mit dem Oberhofmeister Wackerbarth der Kurprinzessin seine Ausgabe des AntiLucretius. Seine im Juli des Jahres gedruckte Rezension ihrer anonym erschienenen Sentimens d'une ame penitente begann mit den Worten: „An diesem Werk ist alles schön, vortrefflich und erhaben “. ${ }^{36}$ Als zur Ostermesse 1749 der Besuch der königlichen Familie bevorstand, entschied sich der noch amtierende Rektor Gottsched am 22. April im Professorenkonzil dafür, vor Maria Antonia Walpurgis „nomine Academiæ die Complimenten“

36 Neuer Büchersaal 7/1 (1748), S. 3-17. 
vorzutragen. ${ }^{37}$ Neben diesem offiziellen Akt gab es ein weiteres Treffen: Gottsched sollte anhand eines Modells - sicherlich aus der Werkstatt des Elbinger Instrumentenbauers Johann Friedrich Endersch ${ }^{38}$ - die Sonnenfinsternis des vergangenen Jahres erläutern. Bei dieser Gelegenheit wurde ihm nicht nur gestattet, das Gedicht auf die Akademiemitgliedschaft der Kurprinzessin persönlich zu übergeben, es wurde sogar die Zeit für den mündlichen Vortrag erübrigt. Daß es sich um eine besondere Auszeichnung handelte, war keine Erfindung Gottscheds. Tatsächlich war „die Überreichung des Gedichtes durch den Autor persönlich ... die erfolgversprechendste, aber seltenste Praxis der Distribution eines Casualgedichts". 39 Die kostbare Uhr, die ihm am Folgetag im Namen des Kurprinzen als Anerkennung zugeschickt wurde, war sicher willkommen, aber der materielle Wert des Geschenks wurde bei weitem durch den ideellen Gewinn überstiegen, der diesem sichtbaren Zeichen der Huld innewohnte. Noch im Maiheft des Neuen Büchersaals wurde die Öffentlichkeit detailliert und gewiß nicht ohne Einverständnis des Hofes über die Vorgänge informiert. Auch für das Kurprinzenpaar entstand ein Gewinn an Renommee, wie beispielsweise die Reaktion Jacob Bruckers zeigt, der den Kontrast zu seiner vergeblichen Bemühung um herrschaftliche Aufmerksamkeit hervorhob (Nr. 153; vgl. auch Nr. 75 und 143). Neben dem Abdruck im Neuen Büchersaal ließ Gottsched die Ode - vermutlich erstmals - separat drucken. 18 Exemplare wurden an den Dresdner Hof verschickt und an die königliche Familie, den Premierund andere Minister verteilt, die, wie der Obersthofmeister der Kurprinzessin Hugo Wilhelm von Wetzel an Gottsched schrieb, die Verse „belobet und

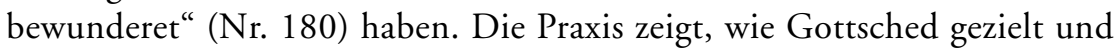
sicherlich mit dem Gedanken an künftige Machtverhältnisse vorging, um für seine Bestrebungen einen Rückhalt am Hof zu gewinnen. Frühere Bemühungen um die landesherrschaftliche Privilegierung der Leipziger Deutschen Gesellschaft waren gescheitert. Mit Johann Ulrich von König und weiteren Personen am Dresdner Hof, die sich der Protektion des Premierministers Heinrich von Brühl sicher sein konnten, war er verfeindet, so daß in den dreißiger und vierziger Jahren seine Spielräume im Dresdner Machtbereich stark beschnitten waren. Die Annäherung an eine Fraktion, die

37 Leipzig, Universitätsarchiv, Rep I/XVI/1 40, Bl. 70r-v, Zitat 70r.

${ }^{38} \mathrm{Vgl}$. unsere Ausgabe, Band 13, S. 75, Erl. 6.

39 Kerstin Heldt: Der vollkommene Regent. Studie zur panegyrischen Casuallyrik am Beispiel des Dresdner Hofes Augusts des Starken. Tübingen 1997, S. 77. 
Brühl kritisch gegenüberstand, war nach Lage der Dinge sinnvoll und sicherte dem Ehepaar Gottsched auf Dauer eine gute Position. ${ }^{40}$

Auch die Strategien der Buchwidmung zielen auf einen Ansehens- und möglichen Einflußgewinn. Gottsched war teils als Berater tätig, wie in diesem Band an den Überlegungen zur Widmung der von der Königsberger Deutschen Gesellschaft vorgelegten Übersetzungen zu zeigen ist, teils war er in eigener Sache aktiv. Nicht nur die Widmung der übersetzten Akademiegeschichte ist hierfür symptomatisch. Gottscheds Vorgehensweise ist im vorliegenden Band vor allem an den Briefen Carl Adolph von Plessens zu verfolgen, mit dem er über den Widmungsempfänger seiner 1749 erschienen Gesammleten Reden ${ }^{41}$ korrespondierte.

Der Briefwechsel der vergangenen Jahre wie auch des Bandes 14 führt vor Augen, daß Gottsched für breit angelegte Untersuchungen auf die Hilfe von Korrespondenten zählen konnte. Seine stattliche Dramensammlung und die daraus hervorgegangenen bibliographischen Veröffentlichungen wie auch die Studien zur älteren deutschen Literatur waren mit Aufrufen verbunden, die jeweils ein beachtliches Echo fanden. Im vorliegenden Band kommt ein weiteres Projekt Gottscheds zur Sprache, das gleichermaßen ohne auswärtige Unterstützung nicht zu bewältigen war: die Sammlung bevölkerungsstatistischen Materials. Es gibt Anhaltspunkte für Gottscheds frühes Interesse an statistischen Angaben. ${ }^{42}$ Im Neuen Büchersaal kommt seine Sachkenntnis gelegentlich zum Vorschein. Gezielte Aktivitäten im größeren Umfang lassen sich aber erst in unserem Briefband verfolgen. So informierte Carl Ludwig Rosner aus Marienburg, wie schwierig die Beschaffung von Angaben bereits im eigenen Ort war. Für Daten aus weiteren preußischen Städten war er vom guten Willen seiner Bekannten und geistlicher Amtsinhaber abhängig. Auch Johann Gottlieb Volkelt in Lauban handelte im Auftrag Gottscheds. Die Schilderung seines Vorgehens vermittelt einen Eindruck vom individuellen Einsatz, der für die Erlangung von Daten erforderlich war. Aus Gera sandte Johann Christoph Pfeiffer einschlägiges Material: „Anbey folgen die verlangte Geraische jahr Zeddel“ (Nr. 160). Geraer Statistiken schickte auch Johann Daniel Heyde, allerdings aus eigenem Antrieb: „Weil ich auch aus Dero beliebten Büchersaale

\footnotetext{
${ }^{40}$ Vgl. Christine Fischer: Instrumentierte Visionen weiblicher Macht. Maria Antonia Walpurgis' Werke als Bühne politischer Selbstinszenierung. Kassel u. a. 2007, S. 65-69.

${ }^{41}$ Mitchell Nr. 394.

42 Vgl. unsere Ausgabe, Band 1, Nr. 43.
} 
ersehen, daß Dieselben den Jahrszetteln einige Aufmerksamkeit geschenket haben, so habe gleichfalls einige aus den hiesigen Gegenden beÿgelegt, besonders einen von unserm Gera" (Nr. 109). Gottsched hat die Befunde dieser und weiterer Orte, über deren Beschaffung wir nicht unterrichtet sind, veröffentlicht. Mit einigem Recht konnte er sich jedenfalls in der Rezension eines einschlägigen Werkes des Pioniers der Bevölkerungsstatistik in Deutschland, Johann Peter Süßmilch, unter die Vorläufer einreihen und erklären: „wir selbst haben uns seit vielen Jahren bemühet, in Sammlung der Geburts= und Todenregister, Beyträge dazu zu liefern“.43 Nachdem sich Süßmilch als Fachmann profiliert hatte, stellte ihm Gottsched Listen sächsischer Städte zur Verfügung, wie aus Süßmilchs Bemerkung hervorgeht, daß „mir der Herr Professor Gottsched eine grosse Sammlung gütigst übersandt hat, wofür ihm hiemit auch öffentlich Dank abstatte“.44

Von einer wachsenden internationalen Reputation zeugt Gottscheds Aufnahme in die Wissenschaftskademie in Bologna. Daß ihm diese Ehrung nicht gleichgültig war, läßt sich nicht allein am Schreiben erkennen, mit dem Gottsched auf die Ernennung reagierte. Auch die Bitte um Bekanntgabe in den Berlinischen Nachrichten und die Tatsache, daß die Mitgliedschaft noch auf Gottscheds Veröffentlichungen des Jahres 1749 vermerkt wurde, spricht für sich. Für Cölestin Christian Flottwell, Gottscheds erfinderischen Lobredner, war die Ernennung nicht so sehr ein Zeichen der Anerkennung Gottscheds, sondern vielmehr „ein neuer Beweiß, daß in Italien die Wißenschaften in voller blüthe stehen" (Nr. 52).

Wie in den vorhergehenden Jahren wurde Gottsched für verschiedene Dienstleistungen in Anspruch genommen. Noch immer kam er als Autor für die Anfertigung von Kasualgedichten in Betracht. Sofern Auftraggeber oder Gegenstand die Interessensphäre Gottscheds berührten, scheint er sich nicht entzogen zu haben. Er schrieb für den Altenburger Kanzler Ernst Friedrich von Seckendorff und lieferte prompt, als der Dresdner Privatsekretär Christian Ehregott Wancke ein Gedicht auf den Konferenzminister Johann Christian von Hennicke erbat, der von Manteuffel gelegentlich als Schutzpatron in schwierigen Fällen ins Spiel gebracht worden war. Nach

43 Das Neueste aus der anmuthigen Gelehrsamkeit 1756, S. 848.

${ }^{44}$ Johann Peter Süßmilch: Die göttliche Ordnung in den Veränderungen des menschlichen Geschlechts, aus der Geburt, dem Tod und der Fortpflanzung desselben erwiesen. 3. Auflage. Berlin 1765. Band 1, S. 197, Anm. Über Süßmilch vgl. RalphJürgen Lischke: Biographisches Lexikon zur Geschchte der Demographie. Hrsg. von Harald Michel. Berlin 2007, S. 292 f. 
dieser Logik dürfte Gottsched auch Friedrich Alexander Lölhöffels Bitte erfüllt und für eine anhaltinische Prinzessin ein Geburtstagsgedicht geschrieben haben - der Verlust der einschlägigen Sammlung ${ }^{45}$ macht eine Überprüfung unmöglich. Auch ein Auftragsgedicht auf den verstorbenen Manteuffel stammte möglicherweise von ihm. Daß er dem Wunsch seines ehemaligen Studenten und jetzigen Hofmeisters Johann Georg Wippert entsprochen hat, für den neunten Geburtstag seines Schutzbefohlenen zu dichten, ist weniger wahrscheinlich.

Hilfeersuchen für Anstellungen erreichten ihn auch von Personen, die über Jahre als Hofmeister und Lehrer eigene Netzwerke geknüpft hatten, aber unversehens wieder ohne Perspektive waren und ihre Erwartungen auf Gottscheds richteten, wie die Briefe Johann Friedrich Barisiéns, Friedrich Groschuffs oder Ernst Gottlieb Litzkendorfs zeigen. „Die Bekanntschafften, welche Eur. Hochedelgeb. mit den erhabensten und angesehensten StandesPersonen in Teutschland haben, und das Ansehen, worinn Dieselben stehen, geben Ihnen Gelegenheit, vieler Glück zu machen“ (Nr. 23). Soweit es sich in einzelnen Fällen erkennen läßt, versuchte Gottsched zu helfen, über die ihm hier zugesprochene Wundertätigkeit verfügte er nicht. Auch Lorenz Christoph Mizlers Hoffnung, mit Unterstützung des Rektors Gottsched an der Leipziger Universität Fuß zu fassen, ging nicht in Erfüllung.

Gottsched wurde gelegentlich auch über delikatere Angelegenheiten ins Vertrauen gezogen. Die Informanten befürchteten jedoch, daß ihre Offenherzigkeit dereinst gegen sie verwendet werden könnte. Rudolf Wedekind ging folglich davon aus, daß Gottsched den Brief mit unfreundlichen Bemerkungen über Albrecht Haller und Interna der Göttinger Deutschen Gesellschaft „post lectionem annihiliren“ (Nr. 11) werde. Scheyb beendete seine Ausführungen über die Machenschaften der Wiener Jesuiten mit den Worten: „Ich bitte diese meine Freÿheit mit dem Caminfeuer zu belohnen, denn sonst wäre ich gar zum Rade verdammt" (Nr. 50). Hartmann von Geusau schließlich schrieb eine Woche, nachdem er Gottsched ausführlich über die abenteuerliche Verhaltensweise seiner Gemahlin und die Trägheit der Weimarer Regierung informiert hatte: „Ultimas meas litteras Vulcano commendo" (Nr. 119).

45 Vgl. Angela Erbacher: Habent sua fata ... - Quellen zur Biographie des Fürsten Franz im Landeshauptarchiv Sachsen-Anhalt, Abteilung Dessau. In: Holger Zaunstöck (Hrsg.): Das Leben des Fürsten. Studien zur Biografie von Leopold III. Friedrich Franz von Anhalt-Dessau (1740-1817). Halle 2008, S. 49-62, 54 und 58. 
Entwicklung des Korrespondentennetzes November 1748 bis September 1749

Der Band enthält 207 Briefe, 13 von ihnen stammen von Gottsched, 183 sind an ihn gerichtet. Luise Adelgunde Victorie Gottsched ist mit vier Briefen vertreten, sieben Briefe nennen sie als Empfängerin.

Im Briefwechsel mit Cölestin Christian Flottwell in Königsberg werden wiederum häusliche, politische, städtische und wissenschaftliche Sachfragen behandelt. Leitthema der Briefe sind die verschiedenen Belange der Königsberger Deutschen Gesellschaft. Gottsched schlug wie in den vergangenen Jahren neue Namen für die Mitgliedschaft vor. Flottwell reagierte: „ihr gütiger Rath bestimmet jederzeit meinen Willen als ein befehl“ (Nr. 71). Er stellte die entsprechenden Mitgliederurkunden aus, klagte aber auch über einen Mangel an Reaktionen oder Bereitschaft zur Mitarbeit und bat Gottsched, dafür zu sorgen, daß die durch seine „Güte gewordene Mitglieder ... wenigstens mit ihren herausgekommenen Schriften unsern Büchervorrath bereichern" (Nr. 71; vgl. auch Nr. 205). Wie schon im Band 13 unserer Ausgabe dokumentiert, hatte Gottsched erheblichen Anteil an der Erarbeitung und Herausgabe von Esprit Fléchiers Lob $=$ und Trauerreden. Besondere Aufmerksamkeit galt der Widmung des Bandes. Ursprünglich und nach Flottwells Vorstellung sollte der Band dem Protektor der Gesellschaft, Obermarschall Johann Ernst von Wallenrodt, gewidmet werden. Dagegen gab es Bedenken, weil Wallenrodt als Protektor Teil der Gesellschaft sei und diese „sich also selbst etwas dediciren“ (Nr. 26) würde, wie das Gesellschaftsmitglied Johann Christoph Kreuschner befand. Als nächster Widmungsempfänger kam Samuel von Cocceji ins Gespräch, der als Verantwortlicher für die Umsetzung der preußischen Justizreform eine machtvolle und einflußreiche Persönlichkeit war und überdies als „OberCurator der Academien“ (Nr. 35) Universitätskarrieren beeinflussen konnte. Als Flottwell, dessen Empfänglichkeit für politische Stimmungen und Gerüchte in den Briefen an Gottsched gelegentlich die Feder führt, zu Ohren gekommen war, daß „widersprechende Befehle des hofes von der zweÿdeutigen Gnade, worinn er stehet, zeugen“ (Nr. 52), wollte er das Risiko, aufs falsche Pferd zu setzen, nicht eingehen. Nach Gottscheds Vorstellung sollte der Band dem preußischen König gewidmet werden. Flottwell scheute davor zurück, da der Band nur Übersetzungen und keine eigenen Texte enthielt. Überdies handelte es sich um Trauerreden. Sollte man, fragte Flottwell ratlos-sarkastisch, die Widmung gegenüber dem Kö- 
nig mit dem Argument begründen, die Gesellschaft „würde sich üben auf seinen Tod eine Gedächtnißrede zu halten"? Flottwell schwenkte ein und meinte zuletzt, daß es Gottsched gelingen könne, „der Dedication einen Schwung zu geben, daß der König aufmerksam werden muß" (Nr. 52). Gottsched übernahm, wie so oft. Flottwell konnte der Entscheidung für den König unterdessen etwas abgewinnen. Er zählte zu den Bewerbern für die seit Februar vakante Professur für praktische Philosophie und sah seine Chancen steigen, wenn es gelänge, den Band mit der Widmung zu einem Zeitpunkt vorzulegen, an dem über die Professur entschieden werden sollte. Er bat Gottsched, „das Werk zu beschleunigen“ (Nr. 71) und verstieg sich wegen Uneinigkeit unter den maßgeblichen Beamten zu dem Gedanken, „wenn nun mein Flechier sich dem Thron des Königes nähern könnte, ehe der König das Gehalt vergiebt, so glaubte ich fast, den Sieg davon zu tragen" (Nr. 88). Nachdem der Band im Mai in Königsberg eingetroffen und Flottwell die von Gottsched verfaßten, aber nicht namentlich unterzeichneten Widmungsverse gelesen hatte, erklärte er euphorisch: „Gott gebe dem Könige 3 Minuten Zeit diese Zuschrift zu lesen, so erhalte ich die Profeßion gewis" (Nr. 123). König Friedrich reagierte mit anerkennenden Worten, erklärte aber seine Neutralität bei Stellenbesetzungen. Dem zuständigen Minister war Flottwell unbekannt, er ging leer aus. Für eine gewisse Unruhe sorgte Gottscheds Vorschlag, die beiden Königsberger literarisch-gelehrten Gesellschaften, Flottwells Deutsche und Christian Heinrich Gütthers Freie Gesellschaft, zu vereinigen. Gottsched hatte dies offenbar im November 1748 angeregt und mehrere Beteiligte damit konfrontiert. Johann Friedrich Reiffstein, der einst Gründungsmitglied und erster Sekretär der Deutschen Gesellschaft war, aber vor Jahren Königsberg verlassen hatte, jubelte und prognostizierte, daß eine vereinigte Gesellschaft „bald eine der berühmtesten werden“ (Nr. 9) würde. Skeptisch äußerte sich hingegen Johann Christoph Kreuschner. Er hielt die Vereinigung für wünschenswert, gab aber doch zu bedenken, daß die Verständigung über den Chefposten problematisch werden könnte. Tatsächlich hing alles an der Bereitschaft der leitenden Gründergestalten, Flottwell und Gütther. Flottwell präsentierte sich wortreich als gehorsamer Vollstrecker des Plans und meinte, „ganz Königsberg würde vor Freude hüpfen v. springen, wenn dieses Werk zu Stande käme“, denn bislang seien an der Haltung zu den beiden Gesellschaften sogar Freundschaften in Mitleidenschaft gezogen worden. Gleichzeitig prognostizierte er Schwierigkeiten, die sich für Mitglieder und insbesondere für die beiden Direktoren hinsichtlich der $\mathrm{Zu}$ - 
ständigkeiten, der Entscheidungsgewalt und in Rangfragen ergeben würden. Er stellte die Bereitschaft zum Verzicht auf eigene Interessen heraus, gab aber die mögliche abschlägige Antwort Gütthers zu bedenken, um schließlich zu empfehlen: „Arbeiten Sie unermüdet, dis Werk auszuführen ... Ziehen Sie von dem die hand ab, der Ihnen nicht folgen will“ (Nr. 4). Gütther hingegen lehnte den Vorschlag unumwunden ab. Zwar brachte er auch Gründe vor: Seine Gesellschaft sei, wie der Name schon sage, an keine Sprache gebunden, ,wir schreiben Latein“. Tatsächlich enthält der Schriftenband der Freien Gesellschaft nur deutschsprachige Texte. Auch das Argument, daß man sich „auch in historischen Sachen“ übe, konnte, wie auch Flottwell bemerkte, nicht als Unterscheidungsmerkmal dienen. Zutreffender war schon der Hinweis, daß die Freie Gesellschaft eine (studentische) Ausbildungsgemeinschaft war - „Meine Absicht ist nur dem Vaterland geschickte Leute zu liefern“ (Nr. 8) -, während die Deutsche Gesellschaft nicht zuletzt durch Gottscheds Zuführungen zunehmend zu einer Honoratioren- oder Statusgemeinschaft mutierte. Der eigentliche Grund lag in unbekannten persönlichen Differenzen. Nach Flottwells Beschreibung, der die frühere Freundschaft erwähnt, die offenbar Schaden genommen hatte und „eine gänzliche Amnestie aller Kleinigkeiten“ (Nr. 4) als Voraussetzung des Zusammenschlusses erforderte, gab es keinen Bruch, sondern eher Empfindlichkeiten. Aus Gütthers Sicht standen der Zusammenarbeit grundsätzliche charakterliche Differenzen im Wege. Er verstand sich als Patrioten und Menschenfreund und vermißte auf der Gegenseite „dergleichen Gesinnungen“. In vornehmer Zurückhaltung fügte er hinzu: „Fragen sie mich nach den Beweisen, ich habe sie an meiner Person erfahren, und ob sie mich gleich geschmerzet, werde ich sie doch mit mir in das Grab nehmen“" (Nr. 8). Damit war das Thema abgeschlossen. Gottsched riet Flottwell, Gütther zu meiden. Aber er respektierte Gütthers Entschluß. $\mathrm{Zu}$ Lebzeiten der Protagonisten war an einen Zusammenschluß nicht zu denken. Nach ihrem Tod stellte sich die Frage erneut, da es keinen plausiblen Grund für das Nebeneinanderbestehen zweier Gesellschaften gab, die sich nahezu denselben Zielen verpflichtet wußten. Am 25. September 1788 wurde die Vereinigung vollzogen. ${ }^{46}$

46 Vgl. Konrad Philipp Dieffenbach: Geschichte der ehemaligen freien Gesellschaft zu Königsberg in Preußen von ihrem Ursprung an, bis zu ihrer Vereinigung mit der Königlichen Deutschen Gesellschaft. Vom Jahre 1743-1788. In: Preußisches Archiv 5 (1794), S. 130-143, 143. 
Gütther widmete dem Thema nur begrenzte Aufmerksamkeit und kam bald auf sein „Hauptwerck ... das ist mein Friedrich“, sein Buch über den ersten preußischen König. Gottsched hatte das Unternehmen seit Jahren begleitet, hatte Verleger vermittelt und nach Verlagsabsagen und den Enttäuschungen wegen der Zensur in Preußen Gütther zur Weiterarbeit ermutigt. Auch die sechs Briefe des vorliegenden Bandes werden von dem Thema beherrscht. Unterdessen hatte Gottsched in dem Breslauer Johann Jacob Korn den passenden Verleger gefunden und den Verlagsvertrag eigenhändig ausgefertigt. Gütther unterrichtete über die durch hohen Beistand gefundenen günstigen Modalitäten der Zensur, erbat Veränderungen des Verlagsvertrages - ihm war am Quartformat des Bandes gelegen -, leitete über Gottsched Anweisungen an den Kupferstecher weiter und bat schließlich, „diesem Kinde, mit dem ich neun Jahr schwanger gegangen, aus der letzern Geburt zu helffen“ bzw. „die Herausgabe des Wercks so schön zu besorgen, als es nur seyn kann“" (Nr. 140). Der Druck des Buchs geschah demnach im Einzugsbereich Gottscheds. Und tatsächlich: Obwohl Johann Jacob Korn auf dem Titelblatt als Verleger angegeben ist, obwohl sich Bernhard Christoph Breitkopf beizeiten aus patriotischen Gründen vom Verlag zurück gezogen hatte: Gedruckt wurde in Leipzig. Am 23. Januar 1750 vermeldete Gütther: „Der Verleger meines Friedrichs, Herr Korn hat mir vor ohngefehr 10 Tagen berichtet, daß er das Werck Herrn Breitkopff zum Druck übergeben habe“.

Johann Friedrich Endersch, der Instrumentenmacher aus Elbing, schickte drei Globen aus seiner Werkstatt, unterrichtete über Arbeiten, Pläne und Beschwerden nach dem Tod seiner Gemahlin und erbat wie schon früher von Gottsched die Zusendung einer speziellen Sorte Zinnasche, die er „sonst nirgents“ (Nr. 55) erwerben könne. Mit gleicher Post erhielt Gottsched einen Brief von Jacob Woit, Gymnasialprofessor für Mathematik sowie wissenschaftlicher Freund und Berater Enderschs. Er schickte die Beschreibung der Sonnenfinsternis ein, die er gemeinsam mit Endersch beobachtet hatte und informierte Gottsched über Geschäftspraktiken des Nürnberger Kartenverlags Homanns Erben: Die Nürnberger planten die Anfertigung von Globen und beauftragten Woit, ihrem Konkurrenten Endersch die Einstellung seiner - auch von Gottsched geschätzten und unterstützten - Globenproduktion nahezulegen.

Gottscheds Verwandter Carl Ludwig Rosner bemühte sich, wie erwähnt, um statistische Angaben über Marienburg und weitere Städte. Er informierte Gottsched über familiäre, meteorologische und schulische Neuigkei- 
ten in Marienburg. Besonderen Raum beansprucht der Bericht über einen Mordfall in Danzig und die besonderen Umstände des Verschwindens der Leiche. Auch die Auseinandersetzungen in der Danziger Bürgerschaft und weitere öffentlich-politische Angelegenheiten der Stadt an der Weichsel wurden von Rosner aufmerksam beobachtet, beurteilt und Gottsched berichtet. Als Marienburger Ratsherr hatte Rosner für die öffentlichen Angelegenheiten benachbarter Städte ein geschärftes Wahrnehmungsvermögen.

Auch aus Danzig selbst kamen Klagen über den bedauernswerten $\mathrm{Zu}$ stand der Stadt. Nach fünfjähriger Pause meldete sich der Rektor Ludolf Bernhard Kemna, der als ehemaliges Mitglied der Nachmittägigen Rednergesellschaft von Gottsched offenbar ein Exemplar der Neuen Proben der Beredsamkeit erhalten hatte. Kemna unterrichtete detailliert über die Pläne zur Besetzung der obersten Pfarrstelle. Aufschlußreich sind Bemerkungen über die Situation des Buchhandels: Werke aus dem Verlag Breitkopf wurden in Danzig nicht angeboten. Aufschlußreich auch die Außenperspektive auf die Königsberger Deutsche Gesellschaft: „Man machet hier keine besondere Vorstellung von derselben. Man will sie gar ganz verächtlich beschreiben" (Nr. 97).

Die 1743 gegründete Danziger Naturforschende Gesellschaft war bei dem Versuch, ihre Publikationen auf eigene Kosten zu vertreiben, wie vergleichbare Unternehmungen späterer Zeit gescheitert, da „sich viel Schwierigkeiten im Verkauf ereignen, und solcher durch die Hrn. Buchhändler nicht wenig gehindert wird“. Gottscheds vorteilhafte Rezension ihrer Versuche und Abhandlungen nahm man deshalb zum Anlaß, über ihn den Verleger Breitkopf für Kauf und Vertrieb der überzähligen Exemplare - von 1000 waren „400 untergebracht worden“ (Nr. 118) - zu gewinnen. In seiner Antwort nannte Gottsched sein Sachinteresse - „Die Natur=Wißenschaft ist seit meinen ersten akademischen Jahren her mein Vergnügen gewesen“ - und die Liebe zum „Vaterland“ (Nr. 125) - Preußen - als Gründe für die Bekanntgabe der Veröffentlichung in seiner Zeitschrift. Infolgedessen setzte er sich wunschgemäß für die Belange der Gesellschaft bei Breitkopf ein.

Auch der Danziger Michael Christoph Hanow nutzte Gottsched als Verbindungsmann zu Breitkopf. Gegen 200 Exemplare seiner 1749 veröffentlichten Programmata erbat er Gottscheds Ausgabe des Bayleschen Wörterbuchs, das bei Breitkopf erschienen war. Den Brief und Exemplare der Danziger Erfahrungen Hanows überbrachte sein Neffe Johann Daniel Titius, der sein Studium in Leipzig aufnahm, später Ältester in Gottscheds 
Gesellschaft der freyen Künste wurde, 1753 die erste komplette Übersetzung der Essays von Michel de Montaigne vorlegte und seit 1756 als Professor der Mathematik und Physik Vorlesungen über zahlreiche Themen hielt und mehrere Zeitschriften veröffentlichte.

Nach längerer Pause meldete sich der Stettiner Hofprediger Jacques de Pérard bei Gottsched, empfahl einen pommerschen Adligen der Aufmerksamkeit Gottscheds und berichtete über seine und von ihm angeregte Akademiemitgliedschaften.

Der schlesische Pfarrer Siegismund Sämler verband Glückwünsche zu Gottscheds Rektorat mit einem vergleichsweise ausführlichen Hinweis auf den bedeutenden Beitrag schlesischer Gelehrter für Entstehung und Gedeihen der Leipziger Universität. Erneut brachte er seine Liebhaberei, die Beschäftigung mit den dinglichen Hinterlassenschaften „der alten Deutschen“ zur Sprache: „Denn das ist Eine von meinen HauptAbsichten ..., die deutschen Alterthümer auff alle weise Brauch und Nutzbahrer zu machen". Sein Haus beherbergte eine beachtliche Sammlung archäologischer Fundstücke, was sich offenbar herumgesprochen hatte und Neugierige anzog. Dem im Frühjahr bevorstehenden „starke[n] Besuch meiner gesamleten Seltenheiten" sah er indes mit gemischten Gefühlen entgegen. Dies galt insbesondere in Bezug auf manch „unvorsichtiges Frauen Zimmer ...: Das steht beÿ solchen Töpffen voller Bewunderung: und voller Bewunderung läst solche auch manch stück aus der Hand fallen" (Nr. 98). Gottsched brachte dem Schlesier große Wertschätzung entgegen. Mehrere seiner Texte wurden im Neuen Büchersaal gedruckt, und Gottsched sorgte für seine Aufnahme in die Königsberger Deutsche Gesellschaft. Mit dem 18. April 1749 endet der überlieferte Briefwechsel.

Als im Jahr 1747 in Paris eine neue Auflage von Chansierces' Les avantures de Neoptolème erschien, rühmte Gottsched das Werk als eine gelungene Arbeit in der Nachfolge des vielgepriesenen Télémaque François de Salignac de La Mothe-Fénelons. Er stellte es dem deutschen Publikum ausführlich vor, wies auf seine Qualität als Sittenlehre hin und wünschte, daß sich wie für den Télémaque „ein guter muntrer Dichter an diesen Neoptolemus machen möchte". Die Reaktion ließ nicht lange auf sich warten. Adam Bernhard Pantke, Gottscheds alter Freund und Kollege aus den frühen Zeiten der Leipziger Deutschen Gesellschaft, seit 1732 Pfarrer im schlesischen Klein-Kniegnitz, schickte schon bald eine Übersetzungsprobe und ließ sich von Gottscheds Ratschlägen und Beifall zur raschen Fortsetzung anspornen. Gottsched beteiligte sich am Gelingen des Werks und 
steuerte auf Wunsch des Übersetzers eine Vorrede bei, die mit Ausführungen über ältere französische Epen und deren frühe deutsche Übersetzungen einen Einblick in den Stand seiner Studien zur älteren deutschen Poesie vermittelt. Schon in diesem Vorwort würdigte Gottsched die Übersetzung Pantkes und in einer Rezension bekräftigte er, daß der Dichter Pantke "nichts von seiner alten Schönheit und Kraft verloren habe“. ${ }^{47}$ Beide verbanden dieselben poetologischen Grundsätze, und so hoffte Pantke, empört über abfällige Bemerkungen gegen den von Gottsched als Vater der deutschen Dichtung apostrophierten Martin Opitz, daß der Kunstrichter Gottsched dieser Schmähung des gemeinsamen Helden Opitz entgegentreten würde.

Die Brüder Carl Benjamin und Johann Ernst Stieff kehrten beide nach dem Studium in Leipzig in ihre Heimatstadt Breslau zurück. Ihre Prägung durch Gottsched und die bleibende Verbindung zum Leipziger Lehrer kommen in ihrer aktiven Rezeption von Gottscheds Veröffentlichungen zum Ausdruck. Johann Ernst, der Mediziner, schickte, angeregt von einem Beitrag im Neuen Büchersaal, Beobachtungen zu einer Sonnen- bzw. Mondfinsternis nach Leipzig. Carl Benjamin, Lehrer an den beiden namhaften Breslauer Gymnasien, reagierte ebenfalls auf einen Beitrag des Neuen Büchersaals und versicherte, daß er seinen Unterricht an Gottscheds großen Werken zur Rhetorik, Poetik und Philosophie orientiere.

In Breslau ist auch das Schreiben des bemerkenswerten Gottfried Michael Kortum entstanden, der an verschiedenen Orten Osteuropas gewirkt und intensive mineralogische und Bergbaustudien betrieben hatte, Mitglied der Leopoldina und seit 1727 als Arzt im oberschlesischen Bielitz tätig war. Er sandte eine vielbeachtete Arbeit über Färbekunst zur Weitergabe an die Breitkopfsche Druckerei an Gottsched. Obwohl er weitere Studien angekündigt hat, konnten Wirkungsspuren Kortums nach dem Jahr 1749 nicht ermittelt werden. Auch in den Biographien seiner beiden namhaften Söhne fehlen genaue Angaben über die Herkunftsfamilie.

Christian Gottlob Stöckel, Stadtsekretär in Brieg, dankte Gottsched für „die Bemühungen beÿ Ausgabe meiner Gedichte“ (Nr. 95). Seine Absicht, kritischen Rezensionen entgegenzutreten und dabei en passant die Verteidigung Gottscheds zu übernehmen, verband er mit der Bitte, Gottsched

47 Neuer Büchersaal 9/1 (1750), S. 57-68, 58. 
möge derartige Beiträge an ihn gelangen lassen, da er seines Amtes wegen kaum Gelegenheit zur Zeitschriftenlektüre finde.

Abraham Gottlob Rosenberg trug, wie erwähnt, Ergänzungen und Bemerkungen zu Gottscheds Sprachkunst vor, die er generell überschwenglich begrüßte. Gegenüber anderen zeitgenössischen wissenschaftlichen Publikationen wie Formeys Logique des vraisemblances oder Werken Georg Friedrich Meiers brachte er hingegen Vorbehalte zur Sprache. Einen großen Raum nehmen Rosenbergs Klagen über den Liegnitzer Verleger David Siegert ein. Nachdem er wegen schlechter Erfahrungen bereits seine Übersetzung der Predigten Jacques Saurins mit dem siebten Band abgebrochen und die Zusammenarbeit mit Siegert eingestellt hatte, führte auch der neuerliche Versuch, die übersetzten Conseils de l'amitié bei Siegert zu veröffentlichen, zu einem Katz- und Maus-Spiel und schlimmen Beschuldigungen gegen Siegert, ohne daß die Zusammenhänge für den Leser restlos klar würden. Siegert beauftragte einen anderen Übersetzer. Um sich gegen die Willkür des Verlegers zu behaupten, nahm Rosenberg das Risiko eines Drucks in eigener Regie auf sich. In gleicher Haltung begab er sich sogar aufs neue an seine Saurin-Übersetzung, obwohl Siegert die fehlenden Bände bereits in anderen Übersetzungen vorgelegt hatte. Die Briefe geben mithin einen Einblick in das Ringen um Selbstbehauptung im Verhältnis Autor-Verleger. In einer Rezension der neuen Rosenbergschen SaurinÜbersetzung wurde die Schelte gegen Eigennutz und Gewinnsucht der Verleger am Beispiel Siegerts und das beklagenswerte Schicksal der unter ihrem Joch arbeitenden Gelehrten öffentlich ausgebreitet. ${ }^{48}$

Im schlesischen Landeshut fühlte sich Ernst Daniel Adami als Konrektor und Kantor "gefangen“ und erinnerte daran, daß ihm Hoffnungen auf eine Pfarrstelle, „das Ziel meiner eintzigen Wünsche“ (Nr. 20), gemacht, aber nicht erfüllt wurden. Angesichts der personellen Situation in der Lehrerschaft der Lateinschule sah er auch im Moment keine Chance auf eine Änderung. Adami strebte die Mitgliedschaft in einer Deutschen Gesellschaft an, mit der er gleichsam seine Leistung als Dichter und Redner bestätigt sehen wollte. Nach Gottscheds Übersendung der Königsberger Mitgliedsurkunde reagierte er überschwenglich auf diesen „Wuchs meiner Ehre“ (Nr. 113).

Den Wunsch, in die Königsberger wie in die Göttinger Deutsche Gesellschaft aufgenommen zu werden, hegte auch Nicolaus Kelz im schlesischen

${ }^{48}$ Vgl. Jenaische gelehrte Zeitungen 1750 (87. Stück vom 4. November), S. 683-685. 
Waldenburg. Er schilderte überdies, mit welcher Emphase Melchior Gottlieb Minor über seinen Besuch der Familie Gottsched berichtet hatte. Dessen Tod hatte ihn nicht zuletzt deshalb schwer getroffen, weil Minor ihm eine erhebliche Beförderung in Aussicht gestellt hatte, ohne dies zu konkretisieren. Mit Minors Tod verschwand diese Perspektive. Kelz bat Gottsched, ihn zumindest über Minors Pläne zu informieren.

Ein in Preußen lebender Schlesier bedachte Gottsched mit einer anonymen Zuschrift, in der er gegen den Breslauer Arzt Johann Christian Kundmann intrigierte. Nach Darstellung des Briefschreibers genossen Gottscheds Urteile im Neuen Büchersaal unangefochtenen Respekt, dank seiner Rezensionen seien ,in Schlesien weniger schlechte Bücher heraus gekommen“. Im Rahmen dieses Feldzugs gegen das Schlechte sollte Gottsched auch Kundmanns Veröffentlichung über die Heuschrecken abstrafen, um, so die Logik des Korrespondenten, „aus redlicher Zuneigung vor die Schlesier, deren Ehre“ zu retten. Zur Erleichterung der Arbeit schickt er „Anmerkungen" über das Buch mit. Gottsched verzichtete wohlweislich auf die Veröffentlichung, Kundmanns Buch findet im Neuen Büchersaal keine Erwähnung. Überdies brachte der Anonymus sein Mißfallen darüber zum Ausdruck, daß finanzielle Zuwendungen an die Berliner Akademie nicht der „Freÿgebigkeit des Monarchen“ (Nr. 16) zu verdanken waren, sondern aus speziellen Steuern für schlesische Mediziner gewonnen wurden.

Johann Gottlieb Volkelt schrieb seinen ersten Brief an Gottsched aus seinem Geburtsort Lauban in der Lausitz. Allem Anschein nach hatte Volkelt Leipzig erst kurz zuvor verlassen. Neben seinen Bemühungen um „Jahreszettel“, auf die schon hingewiesen wurde, erörterte er den Plan, eine „Leipziger Chronick“" zu verfassen. Da Volkelt berichtete, er habe zur Chronik schon „einen Anfang gemacht“ (Nr. 99), liegt die Annahme nahe, daß das Projekt mit Gottsched besprochen, wenn nicht sogar durch diesen in Auftrag gegeben wurde. Es könnte auch sein, daß ein Vorläufer oder ein erster Versuch zu diesem Vorhaben mit Gottsched in Verbindung steht. Im Vorwort zu den Leipziger Merkwürdigkeiten Auf das 1748 Jahr oder, ab zweitem Heft, Leipziger Akademischen Merkwürdigkeiten notierte ihr Verfasser Volkelt: ${ }^{49}$ „Es haben daher die hiesigen Merkwürdigkeiten bey der Universität und der Stadt einem großen Gelehrten dieser hohen Schule, welcher nicht

${ }^{49}$ Vgl. Siegismund Justus Ehrhardt: Evangelische Kirch= und Prediger=Geschichte der Stadt und des Fürstenthums Lignitz. Liegnitz: Johann Gottfried Pappäsche, 1789, S. 316. 
nur selbst durch seine viele gelehrte Schriften das Reich der Wissenschaften erweitert, sondern auch diesen Endzweck auf alle Art zu befördern stets bemüht gewesen, eines besondern Blattes werth geschienen; er hat selbst die Nachricht, und die Einrichtung uns mitgetheilt, und uns auch künftig mit seinem Beytrage zu beehren, sich erkläret. Da sich nun durch seine Vermittelung ein Verleger gefunden, welcher die Ausgabe übernommen, so haben wir uns entschlossen, monatlich zwey Bogen zu liefern" (S. 3). Es liegt nahe, daß der „große Gelehrte“ Gottsched ist. Nicht nur die sachliche und zeitliche Nähe zum Plan der Leipziger Chronik spricht dafür. Auch die Tatsache, daß die Merkwürdigkeiten mit einer ausführlichen Leipziger Geburten- und Totenstatistik beginnen und damit das oben berührte und in Volkelts Brief thematisierte statistische Interesse widerspiegeln, verweisen auf Gottsched. Die „Leipziger Chronick“ kam nicht zustande. Als Hofmeister, der Volkelt 1749 wurde, und erst recht nach Übernahme des Konrektorats in Liegnitz im Jahr 1751 dürfte er weder über die Informationsquellen noch über die Zeit verfügt haben, die ein solches Projekt erforderte. Auch die Leipziger Akademischen Merkwürdigkeiten endeten mit dem vierten Stück bereits im Februar 1748.

Über Johann Christoph Tilings Tätigkeit im ostfriesischen Jever konnte nicht viel in Erfahrung gebracht werden. Seinen wenigen Briefen an Gottsched nach zu urteilen, war er, der Pfarrerssohn, eine Art Privatgelehrter, der Gesellschaften mied, weil dort „die mehrste Zeit mit nichts, als spielen und andern unnüzen Dingen verschwendet" (Nr. 43) und darin auch noch der Sinn gesellschaftlicher Zusammenkünfte gesehen wurde. Obwohl, soweit erkennbar, ohne kirchliches Amt, trat er zuweilen als Prediger in Erscheinung und folgte dabei den Anweisungen Gottscheds, einen klaren gedanklichen Zusammenhang zu entfalten, statt Schriftzitate aneinanderzureihen, was offenbar nicht auf die Gegenliebe seiner Hörer stieß. Tiling beabsichtigte, bei seiner Landesherrschaft mit einer deutschsprachigen Veröffentlichung Aufmerksamkeit zu erzielen, und er bat Gottsched um die Zusage, diesen geplanten und offenbar noch nicht einmal thematisch genauer bestimmten Text vor der Veröffentlichung zu begutachten. Da weitere Briefe Tilings nicht existieren, scheint Gottsched auf die Bitte nicht eingegangen zu sein.

Für seine Ausgabe der Hirtengedichte Vergils hatte Johann Daniel Overbeck eine Vorrede Gottscheds erbeten (Band 13, Nr. 83). Gottsched hatte offenbar zunächst mit der Begründung abgeraten, daß die Gegner Gottscheds dann reflexartig auch gegen dieses Buch eingenommen sein würden. 
Overbeck erklärte, er sei gegen deren Urteile immun, Gottscheds Beifall hingegen sei willkommen. Mit Überlegungen über die angemessene deutsche Bezeichnung der Eklogen Vergils wollte Overbeck in seinem Brief sogleich einen inhaltlichen Beitrag zu Gottscheds erwarteter Vorrede leisten. Nachdem er sich in seinem vorangegangenen Brief von der Hoffnung auf eine akademische Karriere verabschiedet hatte, nahm er Gottscheds Ankündigung, ,mir durch des Herrn von Jerusalem Hochwürden auf der Universität Helmstädt einen Platz zu verschaffen“ (Nr. 83), dankbar auf.

Bezugnehmend auf eine wohlwollende Rezension Gottscheds wandte sich Ludwig Friedrich Hudemann nach zehnjähriger Pause an Gottsched. Mit seiner Hilfe und in der Gewißheit eines gemeinsamen Gegners wollte er einem Hamburger Rezensenten entgegentreten, der seine HeinsiusÜbersetzung ebenso kritisiert hatte wie ein halbes Jahr zuvor die Neuen Proben der Beredsamkeit. Gottsched sollte Hudemanns „kleine Schutzschrift“ „in einer leipzigschen Monathschrift“ (Nr. 157) veröffentlichen. Ob Gottsched reagiert hat, war nicht festzustellen. Der Text erschien ein halbes Jahr später in einer Hamburger Zeitschrift.

Mitunter wirken die Ansinnen, die an Gottsched herangetragen wurden, sonderbar. So wandte sich der inhaftierte Johann Gottlieb Wagner aus dem niedersächsischen Winsen an der Luhe mit der Begründung an Gottsched, er wisse aus seinen Schriften, daß er „einem dörfftigen, das was Ihm mangelt geben könne“, und habe dort auch gelesen, daß er in Königsberg studiert habe, wo er, Wagner, „ansehnliche verwandte“ habe. Mit diesem Fundament an Gemeinsamkeiten bat er Gottsched, das mitgeschickte Schriftgut, das die Schilderung seines Rechtsstreits enthielt, „dem dortigen Collegio Juridico“ zu übergeben und den für den Aktentransport zuständigen „universitäts bedienten“ (Nr. 30) zu nennen. Wie es scheint, war Gottsched die einzige Leipziger Person, deren Namen er kannte. Ob Gottsched die Weiterleitung übernommen hat, läßt sich mangels weiterer Briefe und Akten der Juristenfakultät nicht feststellen.

Die Korrespondenz mit Johann Friedrich Camerer, öffentlichem Hofmeister am Collegium Carolinum in Braunschweig, endet im vorliegenden Band mit einem kurzen Brief, der die Zusendung von Gedichten Camerers begleitete. Möglicherweise hatte sich seine Hoffnung auf Gottscheds „Beÿfall" nicht erfüllt, was daran gelegen haben könnte, daß sich Camerer an „den neuesten Meistern der Dichtkunst“ (Nr. 144) orientiert hat. Über die Entwicklung und besondere Veranstaltungen des Collegium Carolinum wurde Gottsched von Johann Georg Friderici und Johann Friedrich Wil- 
helm Jerusalem unterrichtet. Ihren Wünschen folgend teilte Gottsched einmal mehr die Nachrichten im Neuen Büchersaal der Öffentlichkeit mit. Auch Johann Michael Meißner, der seit Ende seines Studiums in Leipzig Gottsched regelmäßig über seine Unternehmungen informierte, war inzwischen Hofmeister am Collegium Carolinum. Ihm oblag die Betreuung des außerehelichen Sohns des englischen Königs. Die Aufgabe nahm ihn vollständig in Anspruch, so daß die ehedem von Gottsched erbetene Suche nach Manuskripten in Vergessenheit geriet.

Der neue Direktor des Clausthaler Pädagogiums, Johann Daniel Schumann, wollte seine Veröffentlichung über die Schule im Neuen Büchersaal bekanntgeben. Offenbar hielt er die Zeitschrift, ebenso wie seine Braunschweiger Kollegen, für ein geeignetes Medium. Gottsched rühmte das Schulkonzept und sah darin einen weiteren Beleg für die glückliche Orientierung des Schulwesens in Niedersachsen. Nachdem ihm Jahre zuvor von anderer Stelle berichtet worden war, daß der Gebrauch des Deutschen im Schulbetrieb bei den Verfechtern des Latein auf Mißfallen und Widerstand stoße, ${ }^{50}$ konnte Gottsched hier die friedliche Koexistenz beider Sprachen begrüßen und sah sich „bestärkt in der bisherigen Meynung von der Glückseligkeit unsrer Zeiten, da die geschicktesten Schullehrer keine Feinde ihrer Muttersprache sind: sondern sie sowohl, als die alten Sprachen lieben". 51

Nach einer Reise zum Landtag im kurmainzischen Heiligenstadt, die er gemeinsam mit dem Senior der Göttinger Deutschen Gesellschaft Johann Christian Claproth unternommen hatte, wollte Rudolf Wedekind ausführlich über die Erlebnisse berichten, aber völlig unerwartet war Claproth, der mit 29 Jahren eine ordentliche Professur der Rechtswissenschaft in Göttingen übernommen und im Mai seinen 33. Geburtstag gefeiert hatte, nach kurzer Krankheit gestorben. Wedekind konnte nur seinen Schmerz über den Verlust eines Freundes zum Ausdruck bringen. Seine Briefe behandeln, wie berichtet, die Aufnahme der Sprachkunst und weitere Göttinger Interna. Gottsched wurde der Vertrieb eines Gedichtbandes angetragen: „Es wird ia hoffentl. Ew. Wolgeb. nicht viel Mühe verursachen, solche bei einem od. andern buchführer dort abzusetzen, oder quomodocunque an den Mann zu bringen" (Nr. 11). Wedekinds Briefe an Luise Adelgunde Victorie Gottsched schließen an die Orthographiedebatte an, die Wede-

\footnotetext{
${ }^{50}$ Vgl. unsere Ausgabe, Band 3, S. 271, Z. 3-12; Band 10, S. 75, Z. 3-15.

51 Neuer Büchersaal 8/5 (1749), S. 479.
} 
kind herausgefordert und in seiner Zeitschrift Vergnügte Abendstunden publiziert hatte.

Eine Suche nach Handschriften deutscher Poesie in der Bibliothek Georg Christian Gebauers war noch nicht in Angriff genommen worden, wie Gebauer und Jacob Christian Hecker, dem die Durchsicht oblag, erklärten. Hecker versicherte, unterdessen in Wolfenbüttel für Gottscheds Ansinnen geworben zu haben.

Für seine Textsammlung älterer deutscher Dichtung genoß Gottsched vielfältige Unterstützung. Auch Christian Schöttgen, Rektor der Dresdner Kreuzschule und namhafter Historiker, war Gottsched entgegengekommen (Band 13, Nr. 15). Er wandte sich nun in gleicher Angelegenheit an Gottsched und bat um die leihweise postalische Zusendung eines Manuskripts der Leipziger Universitätsbibliothek - als ehemaliger Kustos der Bibliothek kannte er sich in den Beständen aus. Daß der zuständige Bibliothekar Christian Gottlieb Jöcher als alter Freund aus gemeinsamen Leipziger Zeiten zustimmen würde, galt ihm als sicher. Aber für die Ausleihe war das Votum der Professorenschaft vonnöten, ${ }^{52}$ die Fürsprache des Rektors Gottsched dürfte die Entscheidung begünstigt haben.

Schöttgen hatte ehedem Interesse an Melchior Goldasts Gedichtabschriften bezeugt, weil er daraus "historische Nachrichten“ gewinnen wollte. Ganz ähnlich erbat sich der Hallesche Historiker Carl Friedrich Pauli, durch eine Veröffentlichung Gottscheds aufmerksam geworden, Auskunft über die Texte, um für seine Studien zur Geschichte Anhalts und Brandenburgs „einiges Licht“ (Nr. 163) zu gewinnen.

Gottscheds Kontakte in regierungsnahe Kreise beschränkten sich nicht auf Wackerbarth, der gleichwohl nach Manteuffels Tod eine entscheidende Dresdner Adresse wurde. Verbindungen bestanden auch zum Oberhofprediger Johann Gottfried Hermann, der Gottscheds erneuten Hinweis auf seine Predigerqualitäten dankbar registrierte. Über Angelegenheiten der Universität korrespondierte Gottsched wie immer mit dem Chef der zuständigen Behörde, dem Oberkonsistorialpräsidenten Christian Gottlieb von Holtzendorff. Über den Umgang der Universität mit dem kursächsischen Kalenderprivileg wurde schon eingangs berichtet. Als Kalendermacher agierte in Dresden der Magister August Gottlob Böhme. Seinen ausführlichen und erhellend detaillierten Briefen ist zu entnehmen, mit welchen vor allem finanziellen Schwierigkeiten auf einem umkämpften

52 Vgl. unsere Ausgabe, Band 6, S. 177, Z. 6 f. 
und auf staatliche Eingriffe angewiesenen Markt die Kalenderproduktion konfrontiert war. Angesichts der Absicht der Universität, Einnahmeverluste durch Einsparungen an seiner Bezahlung zu kompensieren, verwies Böhme auf den steigenden Aufwand, dem seine Einnahmen schon zuvor nicht entsprachen.

Da sich Johann Friedrich Haas in seinem in Dresden geschriebenen Empfehlungsbrief für einen Landsmann auf Gottscheds ,jedesmahl gegen mich bezeigte Wohlgewogenheit" berief, scheint es verbindliche Kontakte gegeben zu haben. Um so bedauerlicher ist es, daß über die Person und ihren Wirkungsradius in Dresden keine Nachrichten ermittelt werden konnten. Auch Engelbert Heinrich Schwartze, der zur selben Zeit im Dienst des Grafen Heinrich von Bünau in Nöthnitz tätig war wie Johann Joachim Winckelmann - er als "Gerichtshalter“ (Nr. 168), Winckelmann als Bibliothekar - ist in den einschlägigen Lexika nicht aufzufinden. Er sandte einen Beitrag zum Streit um die Elemente der Körper, an dem sich auch Gottsched ehedem beteiligt hatte. Wie Gottsched argumentierte Schwartze gegen die von der Berliner Akademie preisgekrönte Schrift Johann Heinrich Gottlob Justis. Gottsched zeigte infolgedessen die Veröffentlichung wohlwollend an, betonte aber die Differenz von Schwartzes atomistischem Begriff zu den Monaden in Leibniz' Sinn. Schwartze war einst Student Gottscheds, der sein „Lehrmeister im Denken“ (Nr. 134) war. Dank der Gottschedschen Prägung gelinge es ihm, „auch in Gerichts=Sachen mich eines reinen, fließenden und ungezwungenen Ausdruckes zu bedienen“" (Nr. 168).

Knapp zehn Jahre hatte Johann Gottlieb Biedermann, der 1747 das Naumburger Rektorat mit dem in Freiberg vertauscht hatte, nicht an Gottsched geschrieben, als er im Januar 1749 den Wunsch äußerte, seinen ältesten Sohn unter Gottscheds Rektorat in Leipzig immatrikulieren zu lassen. Gottsched reagierte umgehend, nicht ohne sogleich die Frage nach „alten deutschen Gedichten" in der Freiberger Gymnasialbibliothek zu stellen. Biedermann konnte nichts entdecken und kündigte sich erwartungsvoll als Begleiter seines Sohnes an. Zwei Monate später vermeldete er, daß „das Schicksaal mir das Vergnügen und die Ehre mißgönnet, meinen ältesten Sohn Ew. HochEdelgb. zu überbringen“ (Nr. 129). Mehr steht nicht da, Biedermann setzte voraus, daß Gottsched begriff: Carl Siegmund Biedermann war am 16. April im Alter von 16 Jahren gestorben.

Andreas Erlmann, Pfarrer des der Leipziger Universität unterstellten Dorfes Hohenheida, erbat für seinen Sohn ein „testimonium inscriptio- 
nis“, nachdem ihm 15 Jahre zuvor bereits ein „testimonium depositionis“ (Nr. 65) erteilt worden war.

Christian Gottlob Kändler dürfte mit Gottsched noch aus Studienzeiten bekannt gewesen sein, er wurde 1727 in Leipzig zum Magister promoviert. Als Rektor der Stadtschule Sangerhausen entfaltete er eine bemerkenswerte Tätigkeit. Zahlreiche gedruckte Schulschriften und ein Band handschriftlich überlieferter Reden seiner Zöglinge, die in griechischer, lateinischer, französischer und deutscher Sprache ein breites Themenspektrum behandeln, ${ }^{53}$ zeugen vom Engagement des Rektors und dem hohen Niveau der Ausbildung. Kändlers insgesamt sechs überlieferte Briefe aus den Jahren 1734 bis 1749 sind vor allem Empfehlungsschreiben für seine Schüler. Auch im vorliegenden Brief, dem letzten dieser Korrespondenz, legte Kändler ein Wort für einen Absolventen ein: Johann Gottfried Blümner, verwaister Pfarrerssohn aus ärmlichsten Verhältnissen, machte in den folgenden Jahrzehnten in Leipzig eine erstaunliche Karriere. Überdies schickte Kändler den Druck einer von seinen Schülern erarbeiteten und aufgeführten Komödie, die Gottsched als kompetenter Kritiker beurteilen sollte.

Der einzige Brief des Gothaer Generalsuperintendenten Johann Adam Löw im vorliegenden Band enthält die mit dienstlichen Verpflichtungen begründete Absage an eine Einladung, die Gottsched für die unmittelbar bevorstehende Ostermesse an Löw herangetragen hatte. Daß mit dem Besuch konkrete Absichten verbunden waren, ist den Andeutungen Löws zu entnehmen, worin sie bestanden haben könnten, leider nicht.

In Hartmann von Geusaus früheren Briefen kamen Belastungen durch den Rechtsstreit mit dem Herzog von Weimar zur Sprache. Wider Erwarten führte der Tod des Herzogs nicht zu einer Lösung, da der Streit um die Vormundschaft für den minderjährigen Nachfolger eine Entscheidung in seiner Angelegenheit blockierte. Mittlerweile war Geusau durch einen Konflikt mit seiner Gemahlin in Anspruch genommen, die gegen den Willen Geusaus vom Herzog als Pächterin seines Rittergutes in Heygendorf eingesetzt wurde. Ihre notorische Unberechenbarkeit hatte verschiedene Schädigungen verursacht, seit Ende 1748 führte sie eine brutale Auseinandersetzung mit Johann Heinrich Gottlob Justi, der kurz zuvor als Geusaus Gerichtverwalter in Heygendorf eingesetzt worden war und infolge der Auseinandersetzung nur kurz im Amt verblieb. Wohl aus diesem Grund

53 Halle, Marienbibliothek, SHA 61 Fd. 
wird dieser Lebensabschnitt in Justis Biographie nicht eigens erwähnt. Geusau verfaßte den detaillierten Bericht über die Vorkommnisse in seinem „Azyle“ in Beichlingen. Zur Ablenkung - „pour me desennuier“ (Nr. 110) befaßte er sich mit einer Übersetzung, diesmal nicht aus dem Englischen und Französischen, sondern aus dem Griechischen des Homer, die er neben weiteren Übersetzungen Gottsched zur Beurteilung übersandte.

Gottlob Carl Springsfeld war das letzte Mitglied der vormals aktiven Weißenfelser Alethophilengesellschaft, das noch in Weißenfels beheimatet war. Allen anderen Alethophilen war durch den Verlust des herzoglichen Hofes die Existenzgrundlage entzogen, und auch Springsfeld konnte sein Überleben nur dadurch sichern, daß er in den Sommermonaten als Bäderarzt in Karlsbad wirkte. Das spiegelt sich in der Korrespondenz. Nur sein Brief vom Februar 1749, der seinen Bemühungen um Beiträge für die Gedenkschrift auf Manteuffel gewidmet ist, stammt aus Weißenfels. Ein weiterer Brief ist in Karlsbad kurz vor Ankunft des Ehepaares Gottsched verfaßt.

Mit der Frage, ob „die Geschichte der Königin Maria Stuart den Stoff zu einem Trauerspiele geben könne" wandte sich der ehemalige Leipziger Student Georg Christoph Trier aus Meiningen an Gottsched. Die Versicherung, seine „poetische Kenntniß“ (Nr. 155) Gottsched allein zu verdanken, scheint ihm nicht zu einer Reaktion Gottscheds verholfen zu haben. Weitere Briefe Triers liegen nicht vor.

Für Johann Friedrich Barisién hatte sich die Erwartung auf eine Anstellung in fürstlichen Diensten nicht erfüllt. Er mußte sich in seine Heimatstadt Saalfeld begeben, wollte aber „in dieser Barbareÿ“ keinesfalls verbleiben. Gottsched mit seinen Kontakten zu prominenten „StandesPersonen in Teutschland" (Nr. 23) wurde um Hilfe angerufen. Barisién bevorzugte eine Stelle als Reisesekretär oder am Darmstädter Hof, wollte sich aber in alles schicken. Daß er neben dem deutschen Brief in einem französischsprachigen Schreiben vom selben Datum seine Bitte bekräftigte, sollte vermutlich seine sprachliche Eignung unter Beweis stellen.

Wie schon während früherer Reisen Gottscheds wurden seine Belange in Leipzig von Johann Joachim Schwabe wahrgenommen. Er überwachte den Druck von Gottscheds Vorrede zu einer Übersetzung Pantkes, nahm an der Übersetzung der Geschichte der königlichen Akademie der schönen Wissenschaften Korrekturen und Ergänzungen vor, übermittelte Botschaften aus dem Leipziger Bekanntenkreis und kümmerte sich um weitere Aufträge Gottscheds. Ein weiterer Brief aus Leipzig stammt von dem Studenten 
Johannes Carl von Dietrichstein, den Gottsched um ein Empfehlungsschreiben an seine Eltern in Wien gebeten hatte. Nach Auskunft des jungen Grafen hielten sich die Eltern, die der Sohn über den geplanten Wienaufenthalt Gottscheds unterrichtet hatte, auf ihrem Anwesen in Nikolsburg auf. Ein Empfehlungsschreiben, meinte der junge Graf, „brauchet eine so berühmte Persohn wie sie keines" (Nr. 194).

Manteuffels Tod war für Gottsched Anlaß, den Briefkontakt mit Christian Wolff in Halle zu eröffnen. Außer Wolffs Empfehlungsschreiben von 1729 (Band 1, Nr. 88) gab es bis dato keine Korrespondenz zwischen Gottsched und dem Philosophen der deutschen Aufklärung, dessen erfolgreicher Popularisator Gottsched war. Wolff war sofort bereit für einen Beitrag zur Manteuffel-Gedenkschrift. Zur Kommunikation über wissenschaftliche Publikationen, wie sie zwischen Manteuffel und Wolff wie auch zwischen Manteuffel und dem Ehepaar Gottsched Usus war, stand Wolff hingegen nicht zur Verfügung. Eine von Gottsched zur Beurteilung übersandte Schrift zur Monadenlehre habe er, schrieb Wolff, „nicht gelesen, wie dann überhaupt die zeit mir zu edel ist, als daß ich sie auf Lesung der Neuen Schrifften wenden sollte“ (Nr. 165). Während Gottsched seine Interessengebiete als Rezensent und Vermittler ständig erweiterte und in seinen Publikationen Veröffentlichungen über die schönen Künste in verschiedenen Facetten der Öffentlichkeit nahebrachte, konzentrierte sich der Philosoph in Halle auf die Architektur seines Denkens und die Vollendung seines wissenschaftlichen Werks.

Familienbriefe wurden von Gottsched nur in Einzelfällen und eher zufällig aufbewahrt. Insofern genießt der Brief von Friedrich Gottlieb Hichtel mit der Einladung zum Familienbesuch und seinen Auskünften über die Familie, Gottscheds kleinen Paten und die „lieben Obersdorfer“ (Nr. 170) eine Ausnahmestellung. Hichtel war der Schwager des Obersdorfer Pfarrers Christoph Bernhard Gottsched, der, wenig älter als sein berühmter Verwandter, kurz vor diesem den Weg von Königsberg an die Leipziger Universität genommen hatte und in Sachsen verblieben war. Daß unter den wahrscheinlich nicht wenigen Briefen Hichtels dieser überlebt hat, könnte daran liegen, daß neben familiären Belangen auch Buchinteressen zur Sprache kamen.

Als Ausnahme kann auch die Korrespondenz mit dem Reichsgrafen Friedrich Heinrich von Seckendorff bezeichnet werden, da die Schreiben beider Beteiligten vorliegen und darüber hinaus eine bemerkenswerte Kontinuität im Briefverkehr herrschte. Gottsched sorgte durch Bewillkomm- 
nung nach der Rückkehr Seckendorffs von einer Reise nach Franken oder durch Neujahrswünsche dafür, daß die Verbindung keine Unterbrechung litt. Man tauschte sich über die Herrnhuter Brüdergemeine und ihre Bewertung in der Öffentlichkeit aus. Nach der Lektüre einer Rezension bat Seckendorff um die Zusendung der Sprachkunst. Als Seckendorff am 18. Mai seiner Hoffnung auf ein Treffen im Sommer Ausdruck verlieh, brachte Gottsched - fünf Tage vor dem Ereignis - seinen Besuch zur goldenen Hochzeit des Ehepaares Seckendorff ins Gespräch und stellte ein Jubiläumsgedicht in Aussicht. Seckendorff ließ durch seinen Sekretär Carl Franz Strecker sofort ein Willkommen übermitteln, zwei Tage vor dem Fest. Die Gottscheds trafen rechtzeitig ein. Sie hatten „die Ehre, mit unter den vornehmsten Gästen an der ersten Tafel zu seyn, und des leutseligen Umganges der allervornehmsten Personen zu genießen". ${ }^{54}$ Nach der Feier nahm Gottsched selbstverständlich die Publikation der Festansprachen und -gedichte in Angriff und unterbreitete Vorschläge für die Gestaltung. Auch die Briefe Johann Christian Stemlers, der als Generalsuperintendent des Fürstentums Altenburg die Jubiläumspredigt hielt, betreffen das Ehejubiläum. Er bat für den Altenburger Kanzler Ernst Friedrich von Seckendorff, den Neffen des Jubilars, um ein Gedicht. Da der Empfänger etwas auszusetzen hatte, mußte Stemler Gottsched noch einmal bemühen, versah seinen Brief aber mit der Erklärung, er habe den „Auftrag ... sehr ungern auf mich genommen ...; der ich nicht gewohnt bin einem wackern Manne doppelte Mühe zu machen: Vieleicht kennen aber Eur. Magnificenz schon die Art derer Herren, die zum Adel gehören“ (Nr. 121). Sein Unmut rührte vermutlich nicht zuletzt daher, daß ihm, dem hohen Geistlichen, die Rolle des Privatsekretärs zugemutet wurde. Auch die Damen der Familien Sekkendorff und Gottsched korrespondierten miteinander. Im vorliegenden Band kommen zwei französisch geschriebene Briefe der Caroline von Sekkendorff, Ehefrau des Altenburger Kanzlers, an die Gottschedin mit Berichten über familiäre Ereignisse zum Abdruck.

Mehrere Briefe knüpfen an den kurzen Besuch des Ehepaares Gottsched in Gera an. Der in der Auseinandersetzung mit dem Herrnhuter Pietismus engagierte Superintendent Johann Christoph Pfeiffer verfolgte den Gedanken der Veröffentlichung einer Komödie gegen die Herrnhuter, die ihm durch Gottsched bekannt geworden war. Von ihm ist zu erfahren, daß er

${ }^{54}$ Gottsched, Leben der Gottschedin, S. 543. 
für die Nachfolge des verstorbenen Dresdner Superintendenten Valentin Ernst Löscher in Betracht gezogen, aber zu seinem Leidwesen von einflußreichen Personen für ungeeignet befunden worden war.

Johann Daniel Heyde schickte einmal mehr „einen kleinen Beÿtrag zu Dero Sammlung alter Gedichte ... aus des hiesigen Kaufmanns H. Schöbers Büchervorrathe" (Nr. 109). Erstmals ist der Geraer Kaufmann David Gottfried Schöber selbst mit einem Brief vertreten, auch er gedachte des Besuchs. Er sandte Gottsched seine verbesserte Neuausgabe eines Gesangbuches und bat um eine Anzeige "in denen gelehrten Nachrichten“ (Nr. 158). Man kann davon ausgehen, daß die Würdigung der Ausgabe in den Neuen Zeitungen von Gottsched stammt. In Gera traf Gottsched auf einen alten Bekannten, der in den zwanziger Jahren als Mitglied der Deutschen Gesellschaft Gottscheds engerem Freundeskreis angehörte, Georg Christian Wolff. Seit dieser Zeit war das Verhältnis abgekühlt, wenn es denn überhaupt Kontakte gegeben hat. Anknüpfend an eine Unterredung in Gera bat Wolff, seit 1741 gräflich-reußischer Hofrat, um Vermittlung eines Hofmeisters für einen jungen Grafen seines Hauses. In den fünfziger Jahren entwickelte sich ein vergleichsweise lebhafter Briefwechsel.

Der Zwickauer Rektor Christian Clodius ist mit einem Brief vertreten. Wie in vorigen Briefen wurden die wechselseitige Ausleihe älterer Literatur und die Suche nach unbekannten frühen deutschen Dichtungen thematisiert. Nicht zufällig ist der Brief an Luise Adelgunde Victorie Gottsched gerichtet. Clodius' Erklärung, daß Frau Gottsched angekündigt habe, seine „Handreichung in Dero Lied=Historie zu rühmen“ (Nr. 48), bestätigt die Vermutung, ${ }^{55} \mathrm{da} ß$ im Rahmen der geplanten deutschen Literaturgeschichte die Bearbeitung der Lyrik zu diesem Zeitpunkt schon komplett in ihre Hände gelegt war. Erstmals ist Johann Gottfried Weller mit einem Brief vertreten. In den folgenden Jahren gelangten mehr als vierzig Briefe des Zwickauer Geistlichen an Gottsched. Obwohl derzeit erster Diakon an der Katharinenkirche, einst Predigtstätte Thomas Müntzers, beteiligte sich Weller, Gottscheds Bitte folgend, an der Suche nach alten poetischen Texten „in unßrem Bücher Saal“ (Nr. 120), womit offenbar die Ratsschulbibliothek gemeint war. Die wechselseitige Erwähnung zeigt, daß Clodius und Weller gemeinsam mit Gottscheds Projekt befaßt waren.

55 Vgl. unsere Ausgabe, Band 13, S. XII-XIV. 
Seit 1746 wirkte Friedrich Groschuff als Hofmeister im Hause des hessischen Kammerpräsidenten Friedrich Wilhelm von Borck in Kassel, „ob er gleich seiner Jahre und Geschiklichkeit wegen längst eine beßre Versorgung verdienet hätte", wie Johann Friedrich Reiffstein bereits 1746 schrieb (Band 11, S. 422, Z. 6f.). Groschuff war zu dieser Zeit über 50 Jahre alt. $\mathrm{Da}$ „Lutheraner und Ausländer“ - Groschuff stammte aus Danzig - im reformierten Hessen aus im Brief nur angedeuteten Gründen ihr Ansehen verspielt hatten (Nr. 84), zerschlug sich die Hoffnung auf eine Festanstellung bei Hofe. Neben anderen scheint auch Gottsched einen Vorschlag zur „Veränderung“ unterbreitet zu haben, aber es handelte sich um Hofmeisterstellen, während Groschuff „vor das Hofmeisteriren einen rechten Grauen" (Nr. 182) hatte. Groschuffs vollständige Horaz-Prosaübersetzung war unterdessen vollendet. Er sandte den frisch gedruckten ersten Teil unverzüglich nach Leipzig. Gottscheds Anzeige im Neuen Büchersaal erörterte die Gründe für den Verzicht auf eine Versübersetzung und problematisierte Groschuffs Versuch einer Ehrenrettung der Persönlichkeit des Horaz.

Wie sehr Johann Friedrich Reiffstein, der ehemalige Sekretär der Königsberger Deutschen Gesellschaft, auch in Kassel für Angelegenheiten seiner akademischen Heimat zu erwärmen war, zeigt sich in der Begeisterung über die Widmung von Gottscheds Sprachkunst. Er begrüßte Gottscheds Vorschlag zur Vereinigung der beiden Königsberger Gesellschaften. Mit der Empfehlung, zwei prominente Persönlichkeiten des Kasseler Hofes zu Mitgliedern in Königsberg zu küren, wollte er seinerseits zum Ansehen der Gesellschaft beitragen. Gottsched unterstützte das Ansinnen. Wie schon früher erscheint Reiffstein auch im vorliegenden Band als Maler und als Dichter. Er porträtierte die Kinder des hessischen Fürstenhauses, Teile seiner Arbeit verblieben in Gottscheds Besitz. Ein Gedicht zu Gottscheds 49. Geburtstag steigerte sein Ansehen am hessischen Hof, brachte die Mitgliedschaft in der Göttinger Deutschen Gesellschaft zuwege und reizte ihn zu weiteren Versuchen. Als Vorbild und Anregung standen ihm Gellerts Fabeln vor Augen. Die Bitte an Gottsched, geeignete Sujets zu empfehlen, die er mit "dergleichen Einkleidung" (Nr. 82) versehen könnte, wurde umgehend erfüllt.

Im November 1748 hatte Gottscheds Bruder Johann Heinrich nach achtjähriger Witwerschaft wieder geheiratet. Dies und die bevorstehende Reise dürften das Leipziger Ehepaar Gottsched zu dem Entschluß geführt haben, Gottscheds Neffen Maximilian Anfang Mai 1749 aus ihrer Obhut zu entlassen und zu seinem Vater nach Kassel zu schicken. Der Knabe lebte 
seit 1745 in Leipzig und war inzwischen elf Jahre alt. In seinem Gepäck führte er eine Art Führungszeugnis, das von Luise Adelgunde Victorie Gottsched ausgestellt war und nicht eben zu seinen Gunsten ausfiel. Es vermittelt aber auch einen Einblick in die Erziehungspraxis im Hause Gottsched. Sie war überzeugt davon, ihre „Pflichten gegen ihn erfüllet" zu haben. Es habe „nicht an Ermahnungen, sondern blos an seinem Willen gefehlet, denselben Gehör zu geben“ (Nr. 115).

Mit Maximilian Gottsched befassen sich auch die Briefe des Tübinger Universitätskanzlers Christoph Matthäus Pfaff, der sich als Onkel der verstorbenen Mutter des Knaben für dessen Wohlergehen verantwortlich fühlte. Pfaff brachte noch in der Annahme eines dauerhaften Verbleibs in der Leipziger Umgebung große Erwartungen in Ausbildung und Ergehen seines Großneffen zum Ausdruck. Er appellierte an Gottsched, in Maximilian „einen FortPflanzer des beruhmten Gottschedischen Namens" (Nr. 64) zu sehen, rühmte die Leipziger Bildungsatmosphäre, erklärte mit Verweis auf seine eigenen frühen Leistungen, „daß alle die verdorbene Leuthe werden, welche nicht vollkommene humaniora auf die Universitæt bringen" (Nr. 21) und wünschte den baldigen Studienbeginn seines Großneffen.

Johann Christoph Schwarz in Regensburg ist mit einem kurzen Schreiben vertreten, das die Rückzahlung von Schulden begleitete. Gottsched hatte einst die Vergilübersetzung von Schwarz begrüßt und mit einem Vorwort versehen. Nachdem die Übersetzung mit Spott überzogen worden war, der sich auch und insbesondere auf Gottsched richtete, ${ }^{56}$ distanzierte sich Gottsched von dem Werk, ${ }^{57}$ wodurch das Einvernehmen zwischen Gottsched und Schwarz getrübt worden sein dürfte.

Von Friedrich Melchior Grimm, der seiner Abreise nach Paris, dem Ort seiner fulminanten Karriere, entgegensah, liegen drei Briefe vor, die seine Geltung im gehobenen gesellschaftlichen Milieu veranschaulichen. Er fungierte als Mittelsmann adliger Familien, die in Leipzig Personen für verschiedene Dienste akquirieren wollten, und wurde in dieser Position auch aufgefordert, Fragen nach deutschen Äquivalenten französischer Begriffe zu klären, die in der Konversation des bayrischen Kurfürsten entstanden

56 Vgl. Waniek, S. 317, 449-451 u. ö.

57 Vgl. Gottsched: Vorrede. In: Publius Vergilius Maro: Hirtengedichte ... herausgegeben von Johann Daniel Overbeck. Helmstedt: Christian Friedrich Weygand, 1750, S. I-XXXII, If. 
waren. Er sollte, und dies ist wiederum bezeichnend für deren Autorität, die Fragen an die Leipziger Deutsche Gesellschaft und an Gottsched weiterleiten. Grimm erbat mit Nachdruck die Neuauflage seiner Banise, die von der Schauspieltruppe Franz Schuchs in Regensburg aufgeführt werden sollte. Auf Anfrage aus Leipzig gab Grimm Auskunft über die Vertreibung der Juden aus Regensburg und deren gegenwärtigen Status. Man hätte gern gewußt, welches Projekt mit der Anfrage verbunden war.

Die Briefe Jacob Bruckers führen wie immer detailreich und unmittelbar familiäre Belange - die Erkrankung seines in Leipzig lebenden Sohnes und aktuelle publizistische Projekte des Augsburger Pfarrers vor Augen. Er unterrichtete Gottsched über den Stand des Bilder=sals und des Ehren= tempels. Insbesondere ging er auf Bildentwürfe ein, mit denen er für verschiedene Veröffentlichungen betraut worden war. Offenbar hatte Gottsched Bedenken angemeldet, so daß Brucker ausführlich und mit Berücksichtigung älterer Vorbilder, zeitgenössischer ästhetischer Debatten und des Publikumsgeschmacks seine eigenen Arrangements rechtfertigte. Schon mehrfach hatte Brucker in Briefen an Gottsched in freundlicher Übertreibung seinen Sohn beneidet, der in Leipzig die persönliche Bekanntschaft mit Gottsched genießen dürfe, was ihm, Brucker, verwehrt sei. Es ist daher nicht verwunderlich, daß er auf Gottscheds Vorschlag einer Zusammenkunft in Regensburg spontan und begeistert reagierte und seine "ganz auserordentl. Begierde, ein mir von sovielen Jahren her so theures und schäzbares Ehepaar, und einen so erfreul. Gönner von Person kennenzulernen", zum Ausdruck brachte. Allerdings hatte Gottsched Brucker, der bei dieser Gelegenheit erstmals von der Reise des Ehepaares erfuhr, erst am 2. September und kurz vor dem Eintreffen in Regensburg informiert. Brucker erhielt das Schreiben am 3. abends, er reagierte sofort. Sein Terminplan für den Zeitraum war bereits mit „Ammts Arbeiten“ (Nr. 195) gefüllt, ein Treffen in Regensburg war ausgeschlossen. Er schlug statt der Weiterreise auf der Donau eine Fahrt zu Lande vor, die nicht zeitaufwendiger, vielmehr sogar abwechslungsreicher sei und die Begegnung in Augsburg und einen Aufenthalt in München einschlösse. Es erfolgte keine Reaktion, sei es, daß der Brief die Gottscheds nicht rechtzeitig erreichte, sei es, daß sie sich in Schweigen hüllten, weil Änderungen an der Reiseroute keinesfalls in Frage kamen. In seinem letzten Brief des vorliegenden Bandes bedauerte Brucker das „mir so widrige Schicksal“, widmete sich wieder den Berichten über seine Arbeit und erhoffte sich Nachrichten über „allerley wichtige Entdeckungen auf Dero Reise“ (Nr. 202). 
Mit Maria Regina Thomasius in Nürnberg war Gottsched im Sommer 1748 in Kontakt getreten, um poetische Handschriften aus dem Besitz ihres verstorbenen Vaters zu erwerben, was offenbar mühelos gelang. Auf der Reise nach Wien kam eine persönliche Begegnung in Nürnberg zustande. Man blieb fünf Tage, nirgendwo sonst gab es einen längeren Zwischenaufenthalt. Nach den im unmittelbaren Anschluß geschriebenen Briefen zu urteilen, hat die Begegnung in Luise Adelgunde Victorie Gottsched eine tiefe Erschütterung ausgelöst. Mit „blutendem Herzen und einer Wehmut“ beklagt sie den Abschied. Die Tage in Nürnberg waren „die Glückseligsten meines Lebens“. Diese Worte seien bei ihr keine Redensart, sondern „heilig“, sie habe sich ihrer „zu keiner Zeit meines Lebens recht bedienet“ (Nr. 197a). Diese Unmittelbarkeit und Direktheit der Gefühlsäußerung ist ein neuer Ton in ihren Briefen, der sich von der Leichtigkeit und ironischen Distanz früherer Briefe, insbesondere denen an ihren Verlobten Gottsched, deutlich unterscheidet. Frau Gottsched selbst hat die Aura der Einzigartigkeit später etwas abgeschwächt. Tatsächlich stellt die Überlieferung der zwei Briefe nach dem Aufenthalt in Nürnberg einen Sonderfall dar, der uns zu einer besonderen Lösung bei der Wiedergabe genötigt hat. Die Briefe liegen in zwei älteren Drucken vor. Gottsched hat sie in die Gedenkschrift auf seine verstorbene Frau aufgenommen. Seine Textvorlage bilden Abschriften der originalen Briefe aus der Schatulle der Frau Thomasius, die Gottsched zur Verfügung gestellt wurden. ${ }^{58}$ In ihrer Ausgabe der Briefe notierte Dorothea Henriette von Runckel zu ihrer Wiedergabe, sie seien „bereits gedruckt. Ich habe aber kein Bedenken getragen, solche so hier einzurücken, wie sie mir die sel. Frau Gottsched zugeschickt, und wie sie in der Zeitordnung aufeinander folgen. Der sel. Hr. Professor Gottsched erfuhr zu spät, daß sich noch eine verbesserte Abschrift in meinen Händen befand. "59 Die Mitteilung ist in mehrerer Hinsicht aufschlußreich. Zunächst geht daraus hervor, daß Luise Adelgunde Victorie Gottsched im Gegensatz zur Praxis ihres Mannes Abschriften oder Konzepte ihrer eigenen Briefe aufbewahrt hat, zumindest teilweise. Da Gottsched einen weiteren Brief an Frau Thomasius veröffentlicht hat, „so wie ich den Entwurf dazu, unter ihren Briefschaften finde" 60 , stand ihm die Briefsammlung seiner verstorbenen Frau zur Verfügung. Die „verbesserte Abschrift“, von der er „zu spät“ erfuhr, war

\footnotetext{
58 Vgl. L. A. V. Gottsched, Kleinere Gedichte, S. 93.

59 Runckel 2, S. 7.

${ }^{60}$ Gottsched, Leben der Gottschedin, S. 548.
} 
dort ebensowenig enthalten wie die Briefe, die er sich von Frau Thomasius erbitten mußte. Frau Runckel hingegen verfügte über die Abschriften, die ihr schon mit dem Gedanken an einen künftigen Druck zugestellt worden waren, zu dem sie sich von der Gottschedin autorisiert sah: „Wenn jemals meine Briefe gedruckt werden, (waren ihre eigenen Worte:) so sollen Sie die Besorgung davon übernehmen. Ich habe diesen Auftrag erfüllt." ${ }^{1} \mathrm{Da}$ die Herausgeberin betonte, daß ihre Textfassung eine von der Autorin „verbesserte Abschrift" sei, hat offenbar Frau Gottsched selbst die für den Druck bestimmten Briefe überarbeitet. Die Behauptung, daß die Herausgeberin Runckel in großem Ausmaß in den Brieftext eingegriffen habe, ${ }^{62}$ müßte demnach zumindest relativiert werden. Es ist nicht auszuschließen, daß die teilweise erheblichen Veränderungen der Textgestalt Frau Runckel zuzuschreiben sind. Nach dem Befund der Briefe an Frau Thomasius könnten sie aber auch auf Frau Gottsched selbst zurückgehen. Erstaunlich bleibt indes, daß nach den im vorliegenden Band gedruckten Schreiben nur noch ein Brief aus der Thomasiuskorrespondenz vorliegt. Er ist an Gottsched gerichtet und stammt von 1750. Sehr wahrscheinlich wurde die Korrespondenz zwischen den Frauen Gottsched und Thomasius fortgeführt, ohne daß weitere Briefe für die Runckel-Ausgabe zur Verfügung gestellt wurden. Gottsched jedenfalls hat darauf hingewiesen, daß sie schon vor der Begegnung „einen vertrauten Briefwechsel geführet" hatten, ${ }^{63}$ und im Kondolenzbrief nannte Frau Thomasius die verstorbene Gottschedin „Freundinn meiner späten Jahre“. ${ }^{64}$

Die in Erlangen geführten Unterredungen mit dem Professor Georg Wilhelm Pötzinger betrafen vornehmlich Denkmale älterer deutscher Poesie. Sein einziger Brief des vorliegenden Bandes enthält weitere Ausführungen zu diesem Thema.

${ }^{61}$ Runckel 1, Bl. [*7r].

62 Vgl. Magdalene Heuser: Neuedition der Briefe von Louise Adelgunde Gottsched. In: Hans-Gert Roloff (Hrsg.): Editionsdesiderate zur Frühen Neuzeit. Beiträge zur Tagung der Kommission für die Edition von Texten der Frühen Neuzeit. Band 1. Amsterdam; Atlanta 1997, 319-339.

${ }^{63}$ Gottsched, Leben der Gottschedin, S. 544. Er ging von einer größeren Sammlung aus und schrieb an die Adresse von Frau Thomasius: „Vielleicht bekomme ich mehr solche Abschriften von ihren Briefen; um welche ich ergebenst bitte. “ L. A. V. Gottsched, Kleinere Gedichte, S. 93.

64 Thomasius an Gottsched, Nürnberg 14. August 1762. In: Gottsched, Leben der Gottschedin, S. 391-394, 392; vgl. auch S. 394-396. 
Johann Martin Prechtlein, ehedem Rektor in Marktbreit, inzwischen Oberpfarrer in Sommerhausen, hatte Gottsched einst Ausarbeitungen zum Sprachgebrauch zugesandt, die umgehend veröffentlicht wurden. Nach langer Pause wandte er sich noch einmal nach Leipzig, um eingedenk der „weitberühmten Leutseeligkeit" (Nr. 72) des Adressaten einen ehemaligen Schüler zu empfehlen. Die Empfehlung eines Schülers war auch Anlaß für den Brief von Paul Daniel Longolius. Longolius, seit 1735 Rektor in Hof, hatte im selben Jahr sein Studium in Leipzig begonnen, in dem auch der Königsberger Magister Gottsched in Leipzig eintraf. Wie Gottsched war Longolius Hofmeister im Hause Mencke, persönliche Kontakte dürften auch zu Longolius als langjährigem Herausgeber des Zedlerschen Lexikons bestanden haben. Deshalb kann Longolius mit dem Wunsch schließen, daß Gottsched ihm wie einst - „quod olim fecisti“ (Nr. 90) - gewogen bleiben möge.

Anhand der Briefe des Wieners Franz Christoph von Scheyb kann die Planung der Wienreise Gottscheds verfolgt werden. Nachdem sich Scheyb von dem Schrecken über ein Gerücht von Gottscheds Tod erholt hatte, traf ihn die Nachricht vom Tod seines Dienstherrn Friedrich August von Harrach bis ins Mark. Scheyb hatte gehofft, unter Harrachs Schutz sprachlichliterarische Reformen in Gottscheds Geist trotz enormer Widerstände in Angriff nehmen zu können. Die Erarbeitung einer Gedenkrede auf Harrach führte Scheyb auf vermintes Gelände. Er habe, schreibt Scheyb, „manchen scharfen ausdruck ... auslöschen müssen, ... sonst wurden viele nicht ungebrannt, ich aber selbst verbrannt davon gekommen seÿn" (Nr. 166). In Scheybs Sicht waren es immer die Jesuiten, die sich aus Angst vor Machtverlust allen Reformbestrebungen widersetzten. Aus diesem Grunde räumte Scheyb auch Gottscheds Vorschlag, in Wien eine Deutsche Gesellschaft zu errichten, keinerlei Realisierungschance ein.

Unter den Korrespondenzen ins Ausland setzt diejenige mit Angelo Marina Querini den Kontakt fort, den Gottsched mit einem Brief im März 1748 eröffnet hatte (Band 13, Nr. 50). Der Kardinal und Vorsteher der Vatikanischen Bibliothek hielt sein Versprechen: Mit dem Schreiben vom 5. Dezember 1748 gelangte ein Verzeichnis von Handschriften deutscher Dichtungen an Gottsched, die in der Vatikanbibliothek aufbewahrt wurden. Gottsched zeigte sich vom Reichtum der Bestände begeistert, war aber über lateinische Titelangaben hinaus an genauen Beschreibungen der Handschriften interessiert, die, so seine Hoffnung, von deutschen Ordensleuten in Rom vorgenommen werden könnten. Querini versprach Abhilfe 
und erwies sich auch mit seinen Buchgeschenken für Gottsched und die Leipziger Universitätsbibliothek als großzügig. Der Hinweis, daß sich Gottscheds Aufnahme in die Akademie der Wissenschaften zu Bologna seiner Anregung verdankte, wird durch Francesco Maria Zanottis Schreiben aus Bologna bestätigt. Gottsched wollte die Hilfsbereitschaft Querinis noch in anderer Hinsicht nutzen. Er schickte eine Querini gewidmete italienische Übersetzung seines Trauerspiels Der sterbende Cato an den Kardinal, betonte die epochale Bedeutung des Stücks für das deutsche Theater und warb für eine Veröffentlichung. Auf Gottscheds Wunsch hin übergab Querini den Text einem erfahrenen italienischen Übersetzer zur Durchsicht.

Aus dem polnischen Końskie wurden nach langjähriger Pause wieder Briefe von Lorenz Christoph Mizler an Gottsched versandt. Der unvermittelte Anfang des Briefs vom 17. November 1748 legt allerdings die Vermutung nahe, daß seit Dezember 1743 (Band 9, Nr. 176) Kontakte zwischen Mizler und Gottsched bestanden haben. Tatsächlich hatte Mizler wenigstens im Sommer 1747 Leipzig und sicherlich auch Gottsched besucht. In den Briefen unseres Bandes setzte Mizler Gottsched von seinem Wunsch in Kenntnis, Końskie, wo er seit 1743 im Dienst des polnischen Krongroßkanzlers Jan Małachowski stand, zu verlassen, um in Leipzig eine außerordentliche „professionem physices“ (Nr. 12) anzutreten. Er wollte einerseits die räumliche Entfernung zu seinen im Fränkischen lebenden Eltern verringern. Andererseits, und das entpuppte sich als Hauptgrund, wollte er dem Konversionsdruck entgehen, dem er in Polen zunehmend ausgesetzt war. Nachdem die Wege bereits geebnet schienen, mußte er zur Kenntnis nehmen, daß er bei dem sächsischen Premierminister Heinrich von Brühl angeschwärzt worden und der Rückkehrplan auf die Hilfe der Leipziger Professorenschaft angewiesen war. Gottsched sicherte seine Unterstützung zu. Ob eine universitäre Initiative zugunsten Mizlers erfolgte, konnte in den einschlägigen Archiven nicht festgestellt werden. Noch Anfang Februar 1749 gab sich Mizler gewiß, daß er bald „in Leipzig seyn u. bleiben werde“. ${ }^{65}$ Wann und aus welchem Grund der Plan aufgegeben wurde, konnte nicht geklärt werden. Mizler begab sich nach Warschau und war dort als Arzt, Historiker und Journalist erfolgreich. Die überlieferte Korrespondenz mit Gottsched endet mit dem vorliegenden Band. Daß weiterhin Kontakte be-

${ }^{65}$ Mizler an Meinrad Spieß, Końskie 3. Februar 1749. In: Hans Rudolf Jung, HansEberhard Dentler: Briefe von Lorenz Mizler und Zeitgenossen an Meinrad Spiess. In: Studi Musicali 32 (2003), S. 73-196, 120 f., 120. 
standen, ist möglich. Immerhin veröffentlichte Mizler eine polnische Ausgabe der Weltweisheit Gottscheds mit einem Vorwort. ${ }^{66}$

Zahllose Werke Gottscheds enthalten Widmungen. Anhand des Briefwechsels konnte mehrfach beobachtet werden, wie Gottsched Widmungen gezielt vorbereitete und sich über ihre Wirkung informieren ließ. Die im vorliegenden Band gedruckten fünf Briefe des dänischen Adligen Carl Adolph von Plessen beziehen sich auf Gottscheds Absicht, seine Gesammleten Reden dem dänischen König Friedrich V. zu widmen. Daß Gottsched die Vermittlung dem ihm persönlich unbekannten Plessen anvertraut hat, könnte auf Plessens Ruf als Wissenschaftsfreund zurückzuführen sein. ${ }^{67}$ Gottsched dürfte aber auch bewußt gewesen sein, daß sein Name von Manteuffel empfohlen worden war, wie Plessen selbst erklärte. Welche Erwartungen mit der Wahl des Widmungsempfängers verknüpft waren, ist den Briefen Plessens nicht zu entnehmen. Möglicherweise haben die guten Erfahrungen vormaliger Mitarbeiter und Korrespondenten Gottsched stimuliert - Johann Adolph Scheibe wirkte zeitweise als Hofkomponist in Kopenhagen und von Johann Elias Schlegel wußte Gottsched, daß Friedrich V. die pietistische Theaterfeindlichkeit seines Vaters nicht teilte. Schließlich ist an Gottscheds grundsätzliches Interesse an einer deutschdänischen Kulturvermittlung zu erinnern (vgl. unsere Ausgabe, Band 9, S. XIIf.).

Rüdiger Otto

66 Vgl. Mitchell Nr. 750 und die deutsche Übersetzung des Vorworts in: Das Neueste aus der anmuthigen Gelehrsamkeit 1761, S. 138-141.

${ }^{67} \mathrm{Vgl}$. Neuer Büchersaal 9/4 (1750), S. 321. 
